\title{
SELF-VLF Electromagnetic Signals and Solar Wind Proton Density Variations that Preceded the M6.2 Central Italy Earthquake on August 24, 2016
}

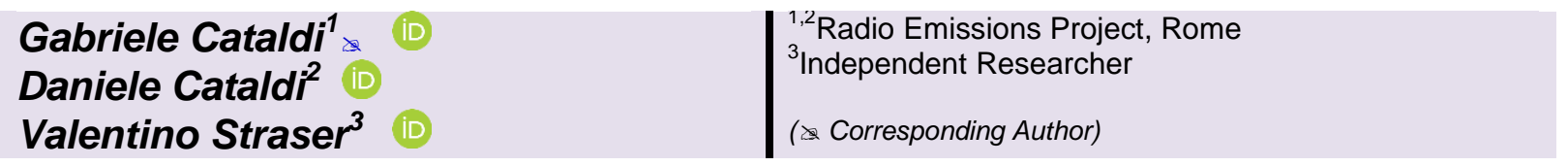

\begin{abstract}
The authors of this study wanted to verify a possible relationship between the M6.2 earthquake, which occurred near Accumoli (RI), Italy on August 24, 2016 at 01:36:33 UTC and solar and geomagnetic activity. In recent years was found that the global M6 + seismic activity is always preceded by an increase in solar activity and the future of scientific research on earthquake prediction will be destined also to the study of the Sun (heliophysics). The analysis of the characteristics of the solar wind "near Earth" and the analysis of the Earth's geomagnetic activity confirmed that the strong M6.2 earthquake recorded in Italy on August 24, 2016 was preceded by an increase in solar activity and in Earth's geomagnetic activity.
\end{abstract}

Keywords: Central Italy Earthquake, SELF-VLF radio anomalies, Solar wind proton density variation, Seismic electromagnetic precursors.

\section{Contents}

1. Introduction

2. Methods and Data.

3. Results .

4. Discussion...

5. Fulmination

6. Conclusion.

References

Citation | Gabriele Cataldi; Daniele Cataldi; Valentino Straser (2017). SELF-VLF Electromagnetic Signals and Solar Wind Proton Density Variations that Preceded the M6.2 Central Italy Earthquake on August 24, 2016. International Journal of Modern Research in Electrical and Electronic Engineering, 1(1): 115.

DOI:

Licensed:

10.20448/journal.526/2017.1.1/526.1.1.15 Crossref

Contribution/Acknowledgement:

Funding:

This work is licensed under a Creative Commons Attribution 3.0 License $(\mathrm{cc})$ EY

Competing Interests:

All authors contributed to the conception and design of the study.

This study received no specific financial support.

Transparency:

The authors declare that they have no conflict of interests.

History:

Ethical:

Publisher:

The authors confirm that the manuscript is an honest, accurate, and transparent account of the study was reported; that no vital features of the study have been omitted; and that any discrepancies from the study as planned have been explained.

Received: 11 October 2016/ Revised: 15 November 2016/ Accepted: 17 November 2016/ Published: 19 November 2016 This study follows all ethical practices during writing.

Asian Online Journal Publishing Group 


\section{Introduction}

On August 24, 2016, at 01:36:33 UTC, an earthquake with a magnitude of Mw6.2 was recorded in Italy at 10km $\mathrm{SE}$ of Norcia and at a depth of 5,3km (Fig.1). The earthquake, which occurred in Umbria, is registered in more than four years after the last strong earthquake M6+ registered in Italy (Emilia-Romagna Region M6.0 earthquake, occurred on May 20,2012) causing the death of 292 people. The most devastated cities by the earthquake have been: Amatrice (RI), Accumoli (RI) and Norcia (PG).

At this moment Europe, United States of America, Japan, Turkey, Russia, Britain, Iran, China and Kyrgyzstan are involved in the study of Electromagnetic Seismic Precursors (SEPs), through public and/or private scientific research projects designed to monitor the natural Earth's electromagnetic field in search of radio emissions (electromagnetic anomalies) that are evident before it is registered a strong earthquake. SEPs are a class of electromagnetic phenomena known in scientific circles since 1880 [1] and studied in the twentieth century by thousands of researchers all over the world. Almost everything that the international scientific community knows about electromagnetic seismic precursors has discovered especially in the second half of last century thanks to the increased availability of radio receivers that can work efficiently in the ELF and VLF bands [2]; [3]; [4]; [5]. Currently, globally, the majority of scientific research projects dedicated to the study of electromagnetic seismic precursors is concentrated on the study of the nature of ionospheric radio emissions above seismic epicenters monitoring the VLF band (3-30kHz) [6]; [7]; [8] while are very few radio stations that monitor the ELF band (3$30 \mathrm{~Hz}$ ) and even fewer monitoring stations that can to descend below $3 \mathrm{~Hz}$ (SELF band). The number of public and private scientific projects that in the world are dedicated to the study of this type of radio signals is very variable because in some cases these projects are bound by economic funds available only for short time and some of these projects cannot have radio stations to do research in first person. Currently is estimated that the number of scientific projects dedicated to the study of electromagnetic seismic precursors can dispose of radio stations for electromagnetic environmental monitoring, does not exceed 10 units, also including the active space missions.

In Italian scientific context this type of research has never found broad debate and the only scientific project dedicated to monitoring of electromagnetic seismic precursors, active $24 \mathrm{~h} 7$, which was capable of producing data that were presented to the international scientific community in recent years, it is the Radio Emissions Project (secondary project placed inside a the wider study program called "LTPA Observer Project"). The electromagnetic monitoring station of Radio Emissions Project is the only electromagnetic monitoring station located on the Italian territory that has been specially created for the study of electromagnetic seismic precursors (SEPs) and the seismic geomagnetic precursors (SGPs), and is also active 24h7 [9]. The station is equipped with two prototypes of radio receivers (Fig. 2) (Fig. 6) made by Dr. Gabriele Cataldi designed to monitor the Earth's natural electromagnetic background between the SELF band $(0<\mathrm{f}<3 \mathrm{~Hz})$ and the VLF band $(3-30 \mathrm{kHz})$ and, potentially, it may be employed to monitor the electromagnetic spectrum up to a frequency of $65 \mathrm{MHz}$.

The heart of the VLF monitoring station is represented by a radio receiver prototype equipped by LM386 chip: a very common operational amplifier in the electronic field capable of working at a bandwidth of $300 \mathrm{kHz}$ and providing an amplification of between 20 and $74 \mathrm{~dB}$. This is the same chip found in the famous receiver "INSPIRE VLF-3" but unlike this last, the prototype developed by Dr. Gabriele Cataldi has a single amplification stage (always represented by the LM386 chip) that provides a gain of $44,95 \mathrm{~dB}(177 \mathrm{x})$. This receiver is connected to a loop antenna of square shape of dimensions of $60 \mathrm{x} 60 \mathrm{~cm}$ containing 50 turns of enameled copper wire of $0.18 \mathrm{~mm}$ diameter. The antenna is aligned in the direction of $310^{\circ} \mathrm{NW}$ and maintains a high directivity in this direction and in the opposite direction, ie at $130^{\circ} \mathrm{SE}$. Instead, it is "blind" to the electromagnetic radiation in the direction of $40^{\circ} \mathrm{NE}$ and $220^{\circ} \mathrm{SW}$ corresponding to the two null points (Fig. 3) (Fig. 4).

The output signal of the VLF receiver prototype is subsequently sent to a 24-bit analog-to-digital converter which is represented by the ADC integrated in the sound card of a notebook computer that is an integral part of the same station (Fig. 2). Here, the analog signals of the VLF receiver are appreciated in relation to their emission frequency and to their intensity and converted to images (spectrograms). The notebook computer also allows powering the VLF receiver via a USB port: this configuration allows to keep powering the receiver on even when the mains power network $(220 \mathrm{~V})$ is not available. The autonomy is one or two hours and in this time frame the station is fully functional.

The second electromagnetic monitoring station is installed on the outskirts of the city of Lariano (RM) (Fig. 5) and is equipped with a radio receiver prototype designed to work efficiently in the SELF-ELF band. The amplification stage of this receiver has been realized using the OP37 Chip, an operational amplifier with professional performance that stands out for having a very low electronic noise level, among the lowest available in the market. The receiver is connected to two antennas: a loop antenna aligned vertically (ie, in the direction of the component "Z" of the geomagnetic field), with circular section and the diameter of $50 \mathrm{~cm}$, containing 25 turns of enameled copper wire with diameter of $0,25 \mathrm{~mm}$; and a coil antenna prototype aligned vertically, containing 350 turns of enamelled copper wire of $0.18 \mathrm{~mm}$ diameter that have been wound on a magnetized metal core. Even this receiver is connected to a notebook computer that allows a 24-bit analog-to-digital conversion of the output signal (Fig 6). As for the VLF monitoring station also the SELF-ELF monitoring station is active $24 \mathrm{~h} 7$ and allows the production of dynamic spectrograms of the recordings made (Fig. 7).

\section{Methods and Data}

To realize this study, the authors analyzed the space weather conditions (near Earth) and the characteristics of the geomagnetic field in the days that preceded the strong earthquake. In particular, the data taken into consideration were: data on the solar activity concern variation in the ionic density of the solar wind detected by the ACE (Advanced Composition Explorer) satellite orbiting the L1 point (Lagrange point) at 1.5 million kilometers from Earth; Solar Wind Density (ENLIL Heliosphere Ecliptic Plane), variations in interplanetary magnetic field or IMF (GOES); X-ray flux (GOES), temporal monitoring of CMEs events or Solar Coronal Mass Ejections (ISWA); monitoring of the coronal holes position on the Sun's surface (NSO/SOLIS-VSM Coronal Hole); Solar Wind 
Velocity (ENLIL Heliosphere Ecliptic Plane); Electron flux (NOAA/SWPC); Magnetopause Standoff Distance (CCMC/RT). The data on geomagnetic activity used for the study are represented by Kp-Index and were provided by Space Weather Prediction Center (SWPC). The data on geomagnetic activity provided by major geomagnetic observatories situated in Northern Europe and the Russian Republic. The data on Geomagnetic and Electromagnetic Environmental Monitoring provided by Radio Emissions Project's Station, located near the cities of Albano Laziale and Lariano, Rome, Italy. The data on M6+ global seismic activity were provided by United States Geological Survey (USGS).

\section{Results}

The results of the study have confirmed the hypothesis of the authors: that the Italian M6.2 earthquake was preceded by an increase of solar and geomagnetic activity, and also confirming also what the authors ascertained from the 2012 data. The authors of this paper have had occasion to explain several times in the international sphere that the global M6+ seismic activity is always preceded by an increase in solar activity and a consequent increase of the Earth's geomagnetic field [10]; [11]; [12]; [13]; [14]; [15]; [16]; [17]. This new seismic prediction method has proven reliable in order to understand when is can expect a resumption of M6+ global seismic activity and could be used internationally as an indicator of seismic risk in the countries where there are potentially destructive earthquakes and tsunamis. Currently, the limit of this new seismic prediction method is to fail to understand with which energy (the minimum expected magnitude is equal to Mw6) and in which place the earthquake hit; and therefore, at least for now this method is reliable to compute forecasts of potentially destructive earthquakes occurring only on a global scale.

\section{Discussion}

A few days before the Italian M6.2 earthquake that was recorded on August 24, 2016 at 01:36 UTC the authors had identified an increase in the solar wind proton density in the proton energy fraction comprised between 310 and $1900 \mathrm{keV}$. This increase began on August 18, 2016 at 12:00 UTC, and the authors were waiting for a resumption of M6+ seismic activity on a global scale. On August 19, 2016 was registered the first M6+ seismic event correlated to the solar wind ionic increase (M7.4 South Georgia Islands region earthquake) and in the following days were recorded another 5 earthquakes for a total of 6 seismic events M6+, among which we find the Italian M6.2 earthquake of 24 August 2016 (Fig. 7). By analyzing the interplanetary medium proton density variation curve near Earth in relation to M6+ global seismic activity occurred from 2012 to today, the authors calculated the average time lag that exists between the start of the proton density increase and the M6+ earthquake that follows it; this is equal to 139.4 hours. In the case of the M7.4 earthquake registered in South Georgia Islands region on August 19, 2016, the time lag was 19 hours and 32 minutes; while for the Italian M6.2 earthquake recorded on August 24, 2016, the time lag was 143 hours 24 minutes. In addition, the Italian earthquake occurred after the peak reached by the proton density variation curve (August 21, 2016, at 12:00 UTC) and this also explains why on Earth was recorded a G1 geomagnetic storm between 23 and 24 August 2016 (Fig. 8).

The analysis of ionic variation of the interplanetary medium has allowed to confirm the observations made by the authors from 2012: also in this case the M6+ earthquakes recorded between 19 and 24 August 2016 were preceded by a solar wind proton density increase. This increase has also interacted with the Earth's magnetosphere generating a Kp-Index increase that has reached two main peaks: the first on August 21, $2016(\mathrm{Kp}=4)$ and the second between 23 and 24 August $2016(\mathrm{Kp}=5)$. The Italian M6.2 earthquake was recorded after the geomagnetic increase began on August 23, 2016 (Fig. 8). These data also confirm that the seismic M6+ activity that occurs on a global scale is always preceded by an increase in solar activity, and the term "solar activity" refers to any electromagnetic phenomenon produced by the sun: the ion flow coming from the Sun is thus a phenomenon related directly to its activities and represent, due to its characteristics, a seismic precursor of interplanetary type (ISP).

Analyzing the telemetry data of the GOES-13 and GOES-15 satellites showed that the Italian M6.2 earthquake of August 24, 2016 was preceded by a perturbation of the interplanetary magnetic field (Fig. 9 and Fig. 10) that occurred 20 hours before. A few minutes before the Italian earthquake, moreover, the interplanetary magnetic field (IMF) presented a drastic reduction that was quantified in about $-25 \mathrm{nT}$ considering the magnetogram provided by GOES-15 satellite. This magnetic disturbance, since it has preceded the strong Italian M6.2 earthquake of about 20 hours, can be considered as interplanetary seismic precursor (ISP). This type of earthquake precursor has been identified for the first time by the authors between 2010 and 2011.

A perturbation of interplanetary magnetic field (IMF) is always associated with an increase in solar activity; in fact This perturbation was accompanied by an increase of the solar wind ion density which reached the Earth at a speed of about $620 \mathrm{~km} / \mathrm{s}$ (Fig. 11) generating a perturbation of Earth's geomagnetic field. This particular is confirmed by polar electromagnetic emission graph (Fig. 12) provided by Community Coordinated Modeling Center (CCMC), as well as by magnetograms provided by Troms $\varnothing$ and Masi Geomagnetic Observatories (Fig. 13 and Fig. 14).

The data provided by the Troms $\varnothing$ (TGO) and Masi (MAS) Geomagnetic Observatory reveal that the Italian M6.2 earthquake recorded on August 24, 2016 was preceded by a strong geomagnetic disturbance began at 12:00 UTC on August 23, 2016. This perturbation was generated by interplanetary medium ionic increase that reached Earth from 18 August 2016. All electromagnetic phenomena produced by interaction between dense solar wind and the Earth's magnetosphere have been defined by the authors as "seismic geomagnetic precursors" (SGPs) because preceding the strong earthquakes occurring on a global scale. Are considered geomagnetic seismic precursors: variations of polar electromagnetic emission; variations in the Earth's geomagnetic field recorded on one or more of the geomagnetic components (vector or angular), and the variation of one or more geomagnetic indices. These electromagnetic phenomena are highlighted when the ion flux from the Sun presents a density increase.

In the last century there was much discussion about the nature of the pre-seismic radio emissions (seismic electromagnetic precursors) detectable in the SELF band $(<3 \mathrm{~Hz})$ and in the first portion of the ELF band $(3-15 \mathrm{~Hz})$ : the most dominant idea was that these emissions should be radio signals of "local" nature, ie electromagnetic 
emissions produced in the earthquake focal zone as a result of the creation of micro-fractures of the rocky substratum [18]; [19]; [20]; [21]; [22]; [23]; [24]. The authors are convinced that one must distinguish the "local" type emissions from those of "no-local" type, because studies that led in the context of environmental electromagnetic monitoring since 2009 have allowed us to understand that radio emissions including between 0,001 and $15 \mathrm{~Hz}$ are not a "local" type emissions but Earth's geomagnetic field disturbances emissions as they are related to space weather conditions (see magnetograms of geomagnetic observatories), and because the Earth's geomagnetic field disturbances can be observed from any point located on the Earth's surface, the authors defined these radio emissions as "no-local" emissions to distinguish them from those produced in the earthquake focal zone as a result of the creation of micro fractures. In this new scientific context is therefore clear that is more correct to define the "no-local" pre-seismic radio emissions as "seismic geomagnetic precursors" (SGPs) and the "local" pre-seismic radio emission as "seismic electromagnetic precursors"(SEPs). An example of pre-seismic electromagnetic emission of "local" type is that recorded by Radio Emissions Project's VLF monitoring station (Fig. 15).

This electromagnetic anomaly that has been recorded on August 18, 2016 between 02:47 UTC and 06:21 UTC, thus remained visible for about 3 hours and 34 minutes between $9.63 \mathrm{kHz}$ and $23 \mathrm{kHz}$, with greater intensity between $9.63 \mathrm{kHz}$ and 20,5kHz and preceded the Italian M6.2 earthquake of the August 24, 2016 of 142 hours and 49 minutes (almost 6 days). Respect to the human radio emissions visible in the spectrogram prevalently between $18 \mathrm{kHz}$ and $26 \mathrm{kHz}$ (indicated by the light blue label at the top of the spectrogram), the radio anomaly has a enormous bandwidth that reaches $13,37 \mathrm{kHz}$. This is the first radio anomaly with these features that has been recorded from the VLF monitoring station of the Radio Emissions from Project since when is operational (2013), perhaps because from 2013 to until August 24, 2016 had not been recorded strong seismic events intensity (M6+) in Italy. By analyzing the geographical location of the VLF monitoring station and Italian M6.2 seismic epicenter related to the aligning of the loop antenna (Fig. 4) has been possible to calculate the angle between the straight line alignment of the loop antenna and the line intersecting the M6.2 earthquake epicenter and VLF monitoring station: this corner is $\approx 60^{\circ}$. Since the loop antenna has the characteristic to be a 'directional antenna", this maintains its maximum sensitivity (100\%) only when the electromagnetic signals that the permeate are parallel to the direction to which it is aligned, while a radio signal that the intersects with an angle of $60^{\circ}$ will be picked up by the loop with a sensitivity that corresponds to $50 \%$ of the total sensitivity:

$\cos 60^{\circ}=1 / 2=0,5$

and thus it can be theorized the possibility that the Radio Emissions Project VLF monitoring station has picked up the "local" pre-seismic electromagnetic radio signal emitted in the focal zone of the earthquake. This radio anomaly was, among other things, the only VLF radio anomaly captured by VLF monitoring station that preceded the Italian M6.2 earthquake occurred on August 24, 2016.

Other interesting data (Fig. 16) were obtained, instead, through the electromagnetic monitoring realized by the SELF-ELF monitoring station of the Radio Emissions Project located on the outskirts of Lariano (RM) (Fig. 5).

SELF-ELF spectrogram shows an increase of the natural electromagnetic background prevalently between 0 and $0,7 \mathrm{~Hz}$ (SELF band) that preceded the Italian M6.2 earthquake of about 2 hours (the magnitude of the main earthquake is indicated by the red square and the yellow vertical line represents the temporal marker). The main peak, indicated by the large red arrow, preceded the M6.2 earthquake of 01:36 UTC of about 70 minutes and then gradually fade and disappear around 02:00 UTC. During this time frame have been recorded some impulsive increases of electromagnetic background that also preceded the three strongest earthquakes occurred after the main one (M6.2), whose magnitude and whose temporal markers are indicated in yellow color. The emission peak identified by the acronym SGP (Seismic Geomagnetic Precursor) represents an intense emission which lasted about 40 minutes and that preceded the M6.2 earthquake of 17 hours.

This type of electromagnetic emissions were defined as "electromagnetic seismic precursors" (SEP) already in the last century and the authors believe that is essential to study them in order to understand how they manifest and the characteristics they have Gokhberg, et al. [25]; Hayakawa and Fujinawa [26]. The authors have had the opportunity to propose at international level the construction of a SELF-ELF and VLF Italian network detection, designed precisely to study the electromagnetic seismic precursors and understand how these are modulated with respect to the place in which they appear. A study project of this type would allow us to understand, in relation to local geodynamic characteristics, what kind of connection have these radios anomalies respect to Earth's geomagnetic field variations and, in general, respect to solar activity; and since the M6+ global seismic activity is related to solar activity and geomagnetic activity, then the seismic trigger must be produced by a form of electromagnetic interaction can alter the static equilibrium of the faults perturbing the accumulated mechanical energy on the fault or influencing geodynamic processes [27].

\section{Fulmination}

To confirm the objectivity of the electromagnetic monitoring related data, the authors have verified if in the vicinity of the two monitoring stations (VLF and SELF-ELF bands) had occurred storms on August 18, 2016 and on August 24, 2016. The radio signals produced by lightning, in fact, can be detected by radio receivers tuned to a wide range of frequencies, for this reason it is essential to reject the hypothesis that electromagnetic anomalies detected near the (VLF and SELF-ELF) electromagnetic monitoring station of Radio Emissions Project are in reality the marks left by a storm. To run this check, were utilized weather data provided by the Italian Air Force (AMI) and found that on August 24, 2016 do not were thunderstorms near the SELF-ELF monitoring station and the only ones thunderstorms were located on South extremity of the Calabria Region, at a distance as the crow flies from $435 \mathrm{~km}$, but have occurred in the afternoon; while on August 18, 2016 there were no thunderstorms near the VLF monitoring station, but light rain were recorded in Northern Italy. Moreover, from a spectrographic point of view, on VLF 
spectrogram and SELF spectrogram are not found typical signals related to lightning discharges, ie the so-called "Spherics" (abbreviation of "atmospherics", also known as "statics").

Other confirmations of a close correlation that had the Italian M6.2 earthquake occurred on August 24, 2016 with the variation of Earth's geomagnetic field comes from the observatory of the Pushkov Institute of Terrestrial Magnetism, Ionosphere and Radio Wave Propagation (IZMIRAN) (Fig. 17).

The magnetogram provided by the Pushcov Institute (Russian Federation) further confirms the data on geomagnetic activity (Kp-Index) provided by the NOAA (National Oceanic and Atmospheric Administration) and the data on the geomagnetic monitoring provided by Troms $\varnothing$ (TGO) and Masi (MAS) Geomagnetic Observatories: the Italian M6.2 earthquake occurred on August 24, 2016 at 01:36 UTC occurred during a G1 geomagnetic storm. The monitoring of the Earth's geomagnetic field through radio receivers designed to work efficiently in the SELFVLF band results to be an indispensable research method to understand how solar activity can influence the M6+ global seismic activity [11]; [15]; [16]. This will represent the challenge that the research on earthquake prediction can no longer shirk in future years, and if the man wants to progress quickly in this scientific field, it will be necessary to create interdisciplinary research center dedicated to the study of the geomagnetism, heliophysics, geodynamics and space weather.

Another interesting fact comes from another electromagnetic monitoring station located in the city of Trasaghis (UD), in Italy, which forms part of Friuli Experimental Seismic Network (FESN), the first European amateur local experimental seismic network born from the tragic experience caused by the earthquake occurred in Friuli on May 1976 (Fig. 18).

The magnetogram provided by the FESN's network, was realized through an environmental electromagnetic monitoring station (located in Trasaghis, Udine) designed for the study of electromagnetic seismic precursors detectable in SELF bandwidth $(<3 \mathrm{~Hz})$ and in the ELF band $(3-30 \mathrm{~Hz})$. On the day August 21, 2016 between 08:40 UTC and 09:35 UTC the monitoring station has detected an electromagnetic anomaly of high intensity which had a maximum bandwidth of about $1.8 \mathrm{~Hz}$. The anomaly has preceded the Italian M6.2 earthquake occurred August 24, 2016 of about 65 hours.

\section{Conclusion}

The Earth's electromagnetic background monitoring in the SELF-VLF band ( $<3 \mathrm{~Hz}-30 \mathrm{kHz})$ is a methodology of scientific investigation that has allowed to demonstrate the existence of SEPs [28]. The studies that the authors have realized within this new scientific context (as well as technological) have allowed us to understand that there are actually two families of pre-seismic radio emissions: 1) radio emissions identified as Earth's geomagnetic field disturbances related to "near Earth" solar wind proton density increase variations, and for this reason it can be seen from any point on the Earth (this is "no-local" type emissions); 2) radio signals are not connected directly to the solar and geomagnetic activity: these radio signals are probably generated by piezoelectricity phenomena occurring near the focal area of the earthquake and are detectable near earthquake epicenter (this is a "local" type emissions). It is therefore clear that the monitoring of solar activity and Earth's geomagnetic activity is an activity of fundamental importance to be able to have a general understanding of pre-seismic radio signals nature [29]; [30]; [31].

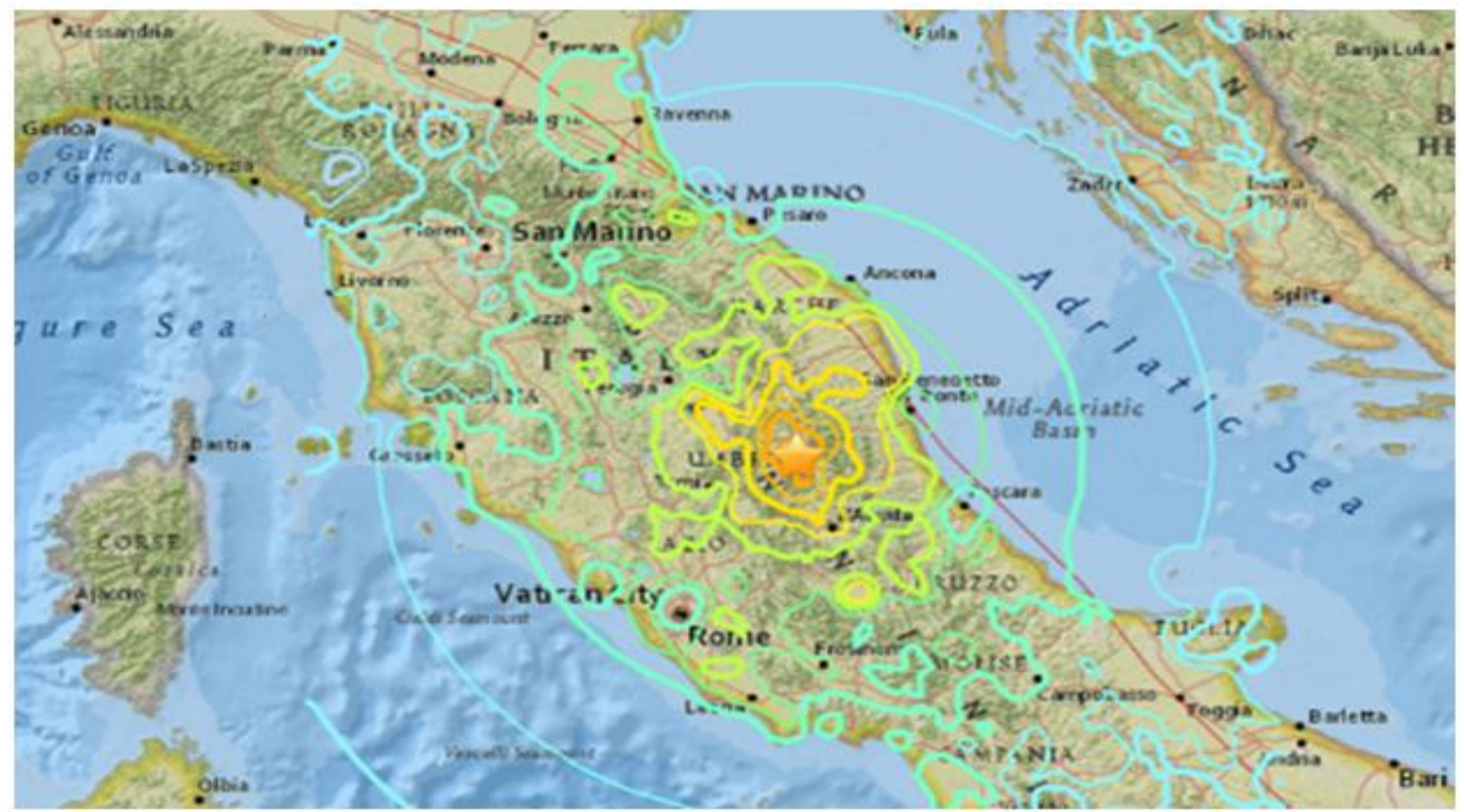

Fig-1. Italian M6.2 earthquake epicenter. The picture shows the seismic epicenter of M6.2 earthquake occurred in Italy on August 24,2016 at 01:36:33 UTC, Lat.: $42.720^{\circ} \mathrm{N}$ Long.: $13.182^{\circ} \mathrm{E}$. Concentric colored lines represent a measure (colorimetric scales) of the energy dispersion of the earthquake measured in magnitude (Mw). USGS not indicated on map the value in magnitude respect to the color. Credit: United States Geological Survey (USGS).

Source: http://earthquake.usgs.gov/earthquakes/eventpage/us10006g7d\#map

In fact, as the authors demonstrated that all M6+ earthquakes that occur on a global scale are always preceded by an increase of the solar wind proton density near Earth, the solar and geomagnetic activity monitoring is a seismic prediction method that has proven reliable for understanding when we can expect a recovery of the M6+ global 
seismic and could be used internationally as an indicator of seismic risk in the countries where there are potentially destructive earthquakes and tsunamis. While, the Earth's electromagnetic field monitoring activities can provide a methodology of scientific investigation which would allow to understand exactly where the strong earthquake would strike through the use of electromagnetic monitoring stations able to understand where come from the pre-seismic radio emission of "local" type [28]. This technology is known as "radio direction finding" (RDF), and is also widely used in amateur fields.

The study of solar magnetic field connected to solar coronal mass ejections and the solar activity study, in general, through the satellite data and the geomagnetic data will represent a fundamental tool in the future for the prediction of potentially destructive earthquakes [32]; [33]; [34]; [35]; [36]; [37]; [38]; [39]; [40]; [41]; [42]; [43]; [44]; [45]; [46]; [47]; [48]; [39].

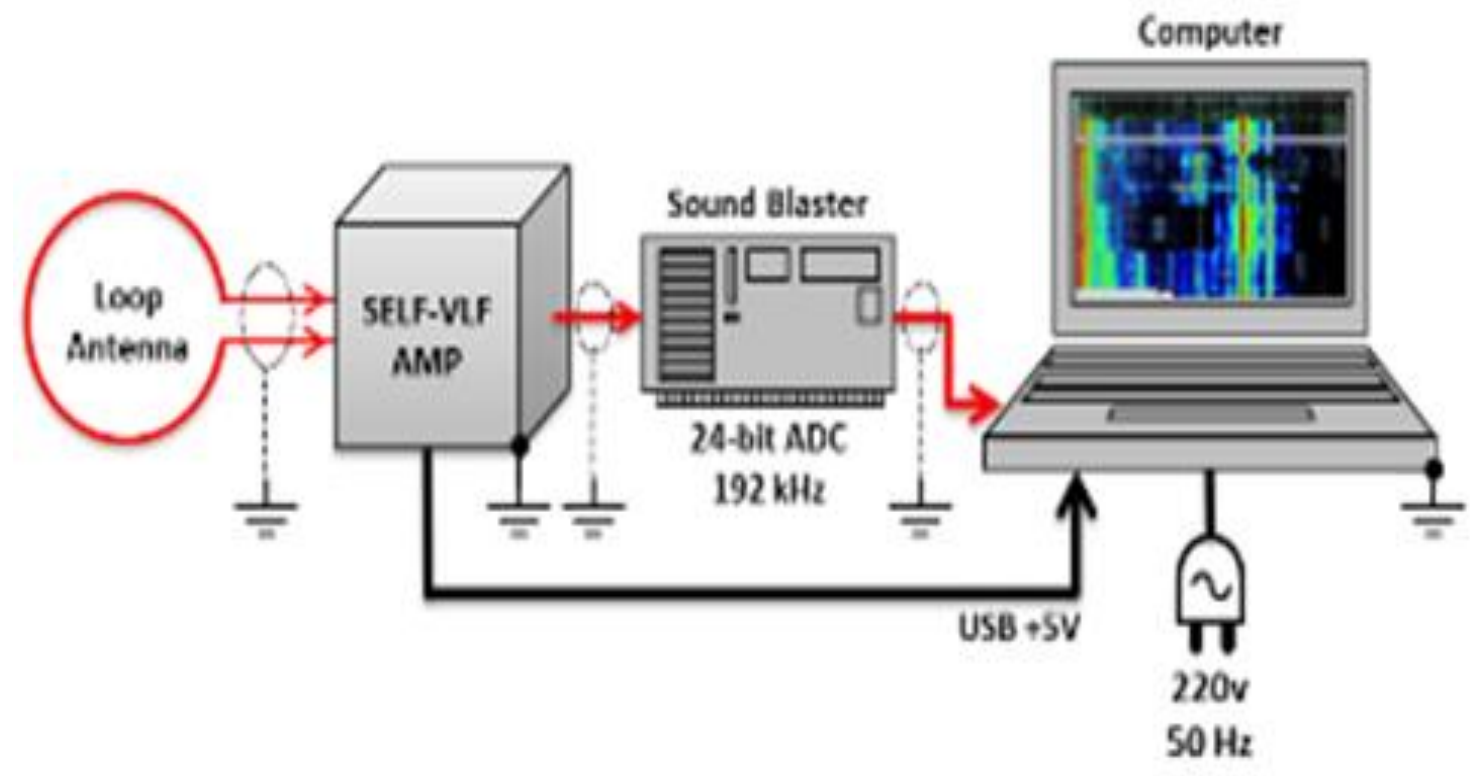

Fig-2. VLF monitoring station of Radio Emissions Project. The top image is the schematic representation of the hardware connections of the VLF electromagnetic monitoring station that was created by Dr. Gabriele Cataldi in the city of Albano Laziale (RM), Italy. The station is dedicated to the monitoring of electromagnetic seismic precursors (SEPs) which are observed between the band SELF $(0<\mathrm{f}<3 \mathrm{~Hz})$ and the band VLF $(3-30 \mathrm{kHz})$. Source: http://www.ltpaobserverproject.com/radio-emissions-project-elf---slf---ulf---vlf.html
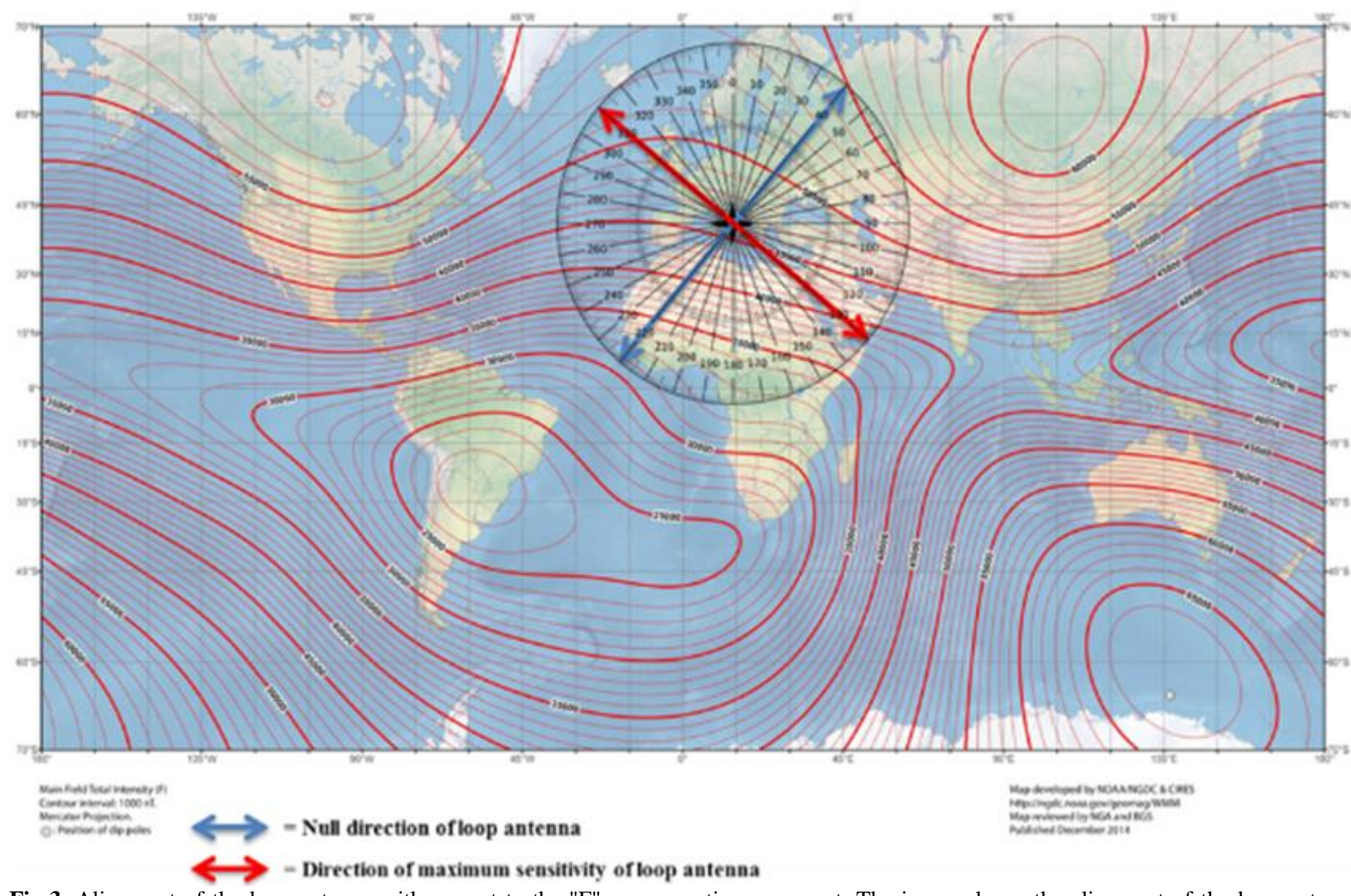

Fig-3. Alignment of the loop antenna with respect to the "F" geomagnetic component. The image shows the alignment of the loop antenna which is equipped the Radio Emissions Project's VLF monitoring station with respect to the "F" geomagnetic component. The red line provided with arrows at end represents the direction in which the loop antenna retains its maximum sensitivity $\left(210^{\circ} \mathrm{NW}-130^{\circ} \mathrm{SE}\right)$ to the magnetic component. The blue line provided with arrows at the ends represents the direction in which the loop completely loses its sensitivity $\left(40^{\circ} \mathrm{NE}-220^{\circ} \mathrm{SW}\right)$ and is "blind" to the magnetic radiation. Credits: US/UK World Magnetic Model - Epoch 2010.0 - Main Field Total Intensity (F) and Loop Antenna Alignment.

Source: https://www.ngdc.noaa.gov/geomag/WMM/DoDWMM.shtml 


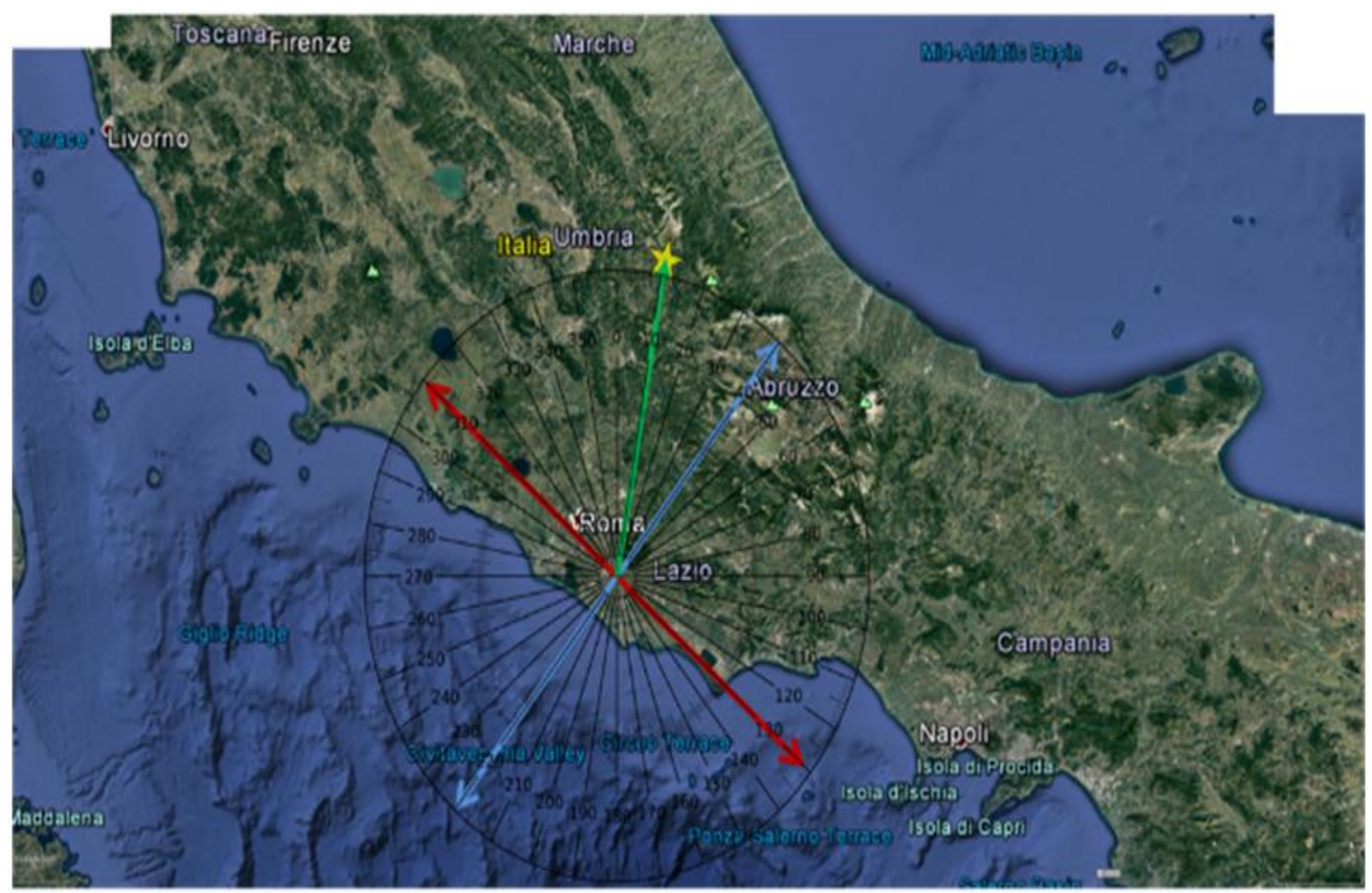

\section{$\longleftrightarrow=$ Null direction of loop antenna \\ $\longleftrightarrow=$ Direction of maximum sensitivity of loop antenna \\ $\longrightarrow=$ Direction of Italian M6.2 earthquake epicenter}

\section{$\vec{y}=$ Italian M6.2 earthquake epicenter}

Fig-4. Alignment of the loop antenna respect to te Italian peninsula. The image shows the alignment of the loop antenna which is equipped the Radio Emissions Project's VLF monitoring station with respect to the Italian peninsula. The red line provided with arrows at end represents the direction in which the loop antenna retains its maximum sensitivity $\left(210^{\circ} \mathrm{NW}-130^{\circ} \mathrm{SE}\right)$ to the magnetic component. The blue line provided with arrows at the ends represents the direction in which the loop completely loses its sensitivity $\left(40^{\circ} \mathrm{NE}-220^{\circ} \mathrm{SW}\right)$ and is "blind" to the magnetic radiation. The yellow star indicates the epicenter of the Italian M6.2 earthquake occurred on October 24, 2016: This is located at $10.6^{\circ} \mathrm{NE}$ direction and at a distance as the crow flies approximately of $123 \mathrm{~km}$ (green arrow) respect to Radio Emissions Project's VLF monitoring station site. Credits: Google Maps.

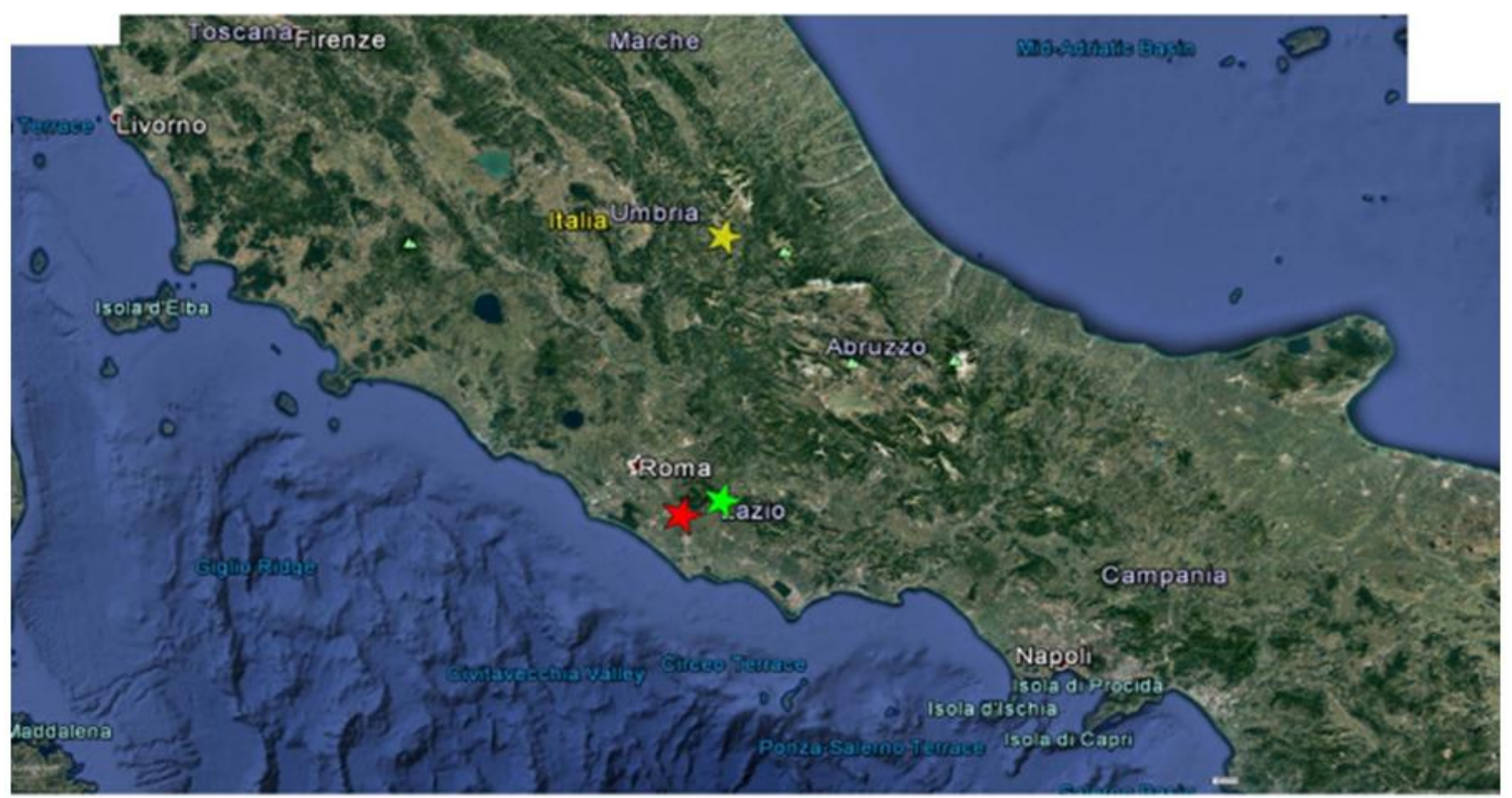

1) - Radio Emissions Project VLF Monitoring Station Lat: $41^{\circ} 42^{\circ} 7.52^{\prime \prime} \mathrm{N}$ - Long: $12^{\circ} 49^{\prime} 17.34^{\prime \prime} \mathrm{E}$

\section{$\checkmark=$ Italian M6.2 earthquake epicenter Lat: $42.720^{\circ} \mathrm{N}$ - Long: $13.182^{\circ} \mathrm{E}$} C. Radio Emissions Project SELF-ELF Monitoring Station
Lat: $41.729535^{\circ} \mathrm{N}$ - Long: $12.840968^{\circ} \mathrm{E}$.

Fig-5. SELF-ELF monitoring station. The picture shows where is the SELF-ELF monitoring station of Radio Emissions Project compared to the Italian peninsula and the city of Rome. Credits: Google Maps. 


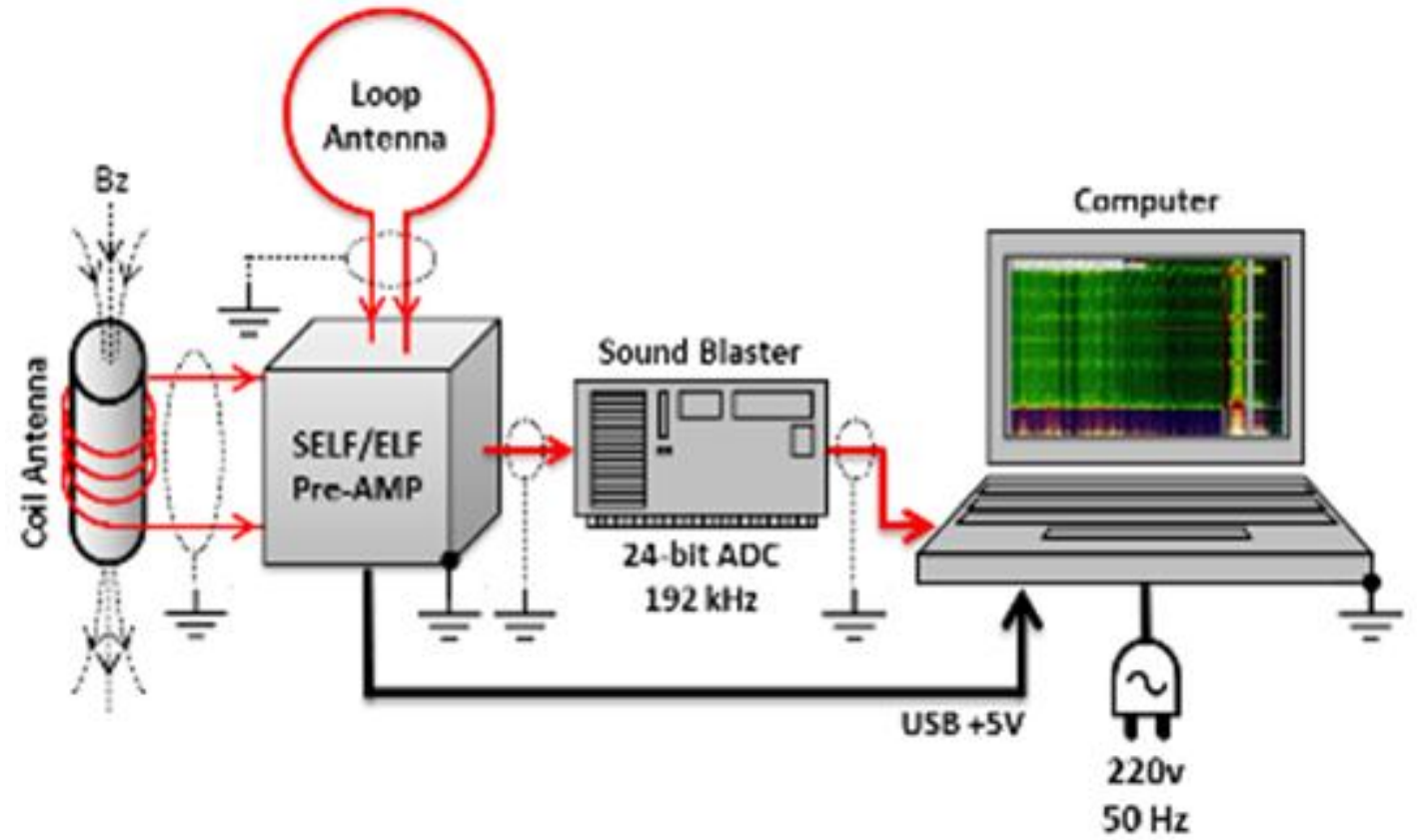

Fig-6. Stazione di monitoraggio SELF-ELF del Radio Emissions Project. The top image is the schematic representation of the hardware connections of the electromagnetic monitoring station SELF-ELF that was created by Dr. Gabriele Cataldi near the city of Lariano (RM), Italy. The station is dedicated to the monitoring of electromagnetic seismic precursors (SEPs) which are observed between the SELF band $(0<\mathrm{f}<3 \mathrm{~Hz})$ and the ELF band $(3-30 \mathrm{~Hz})$.

Source: http://www.ltpaobserverproject.com/radio-emissions-project-elf---slf---ulf---vlf.html

\section{Interplanetary and Geomagnetic Precursors}

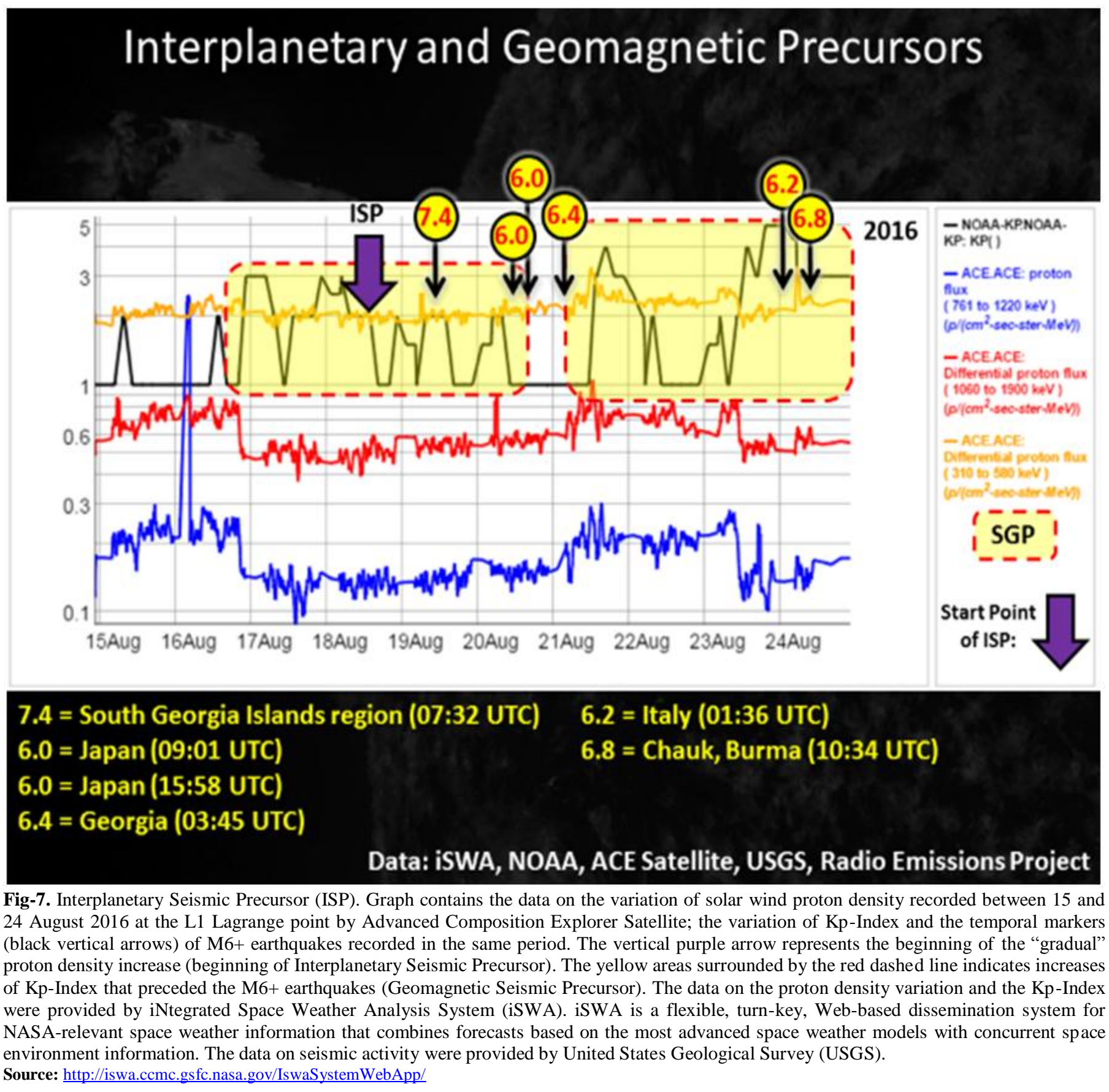




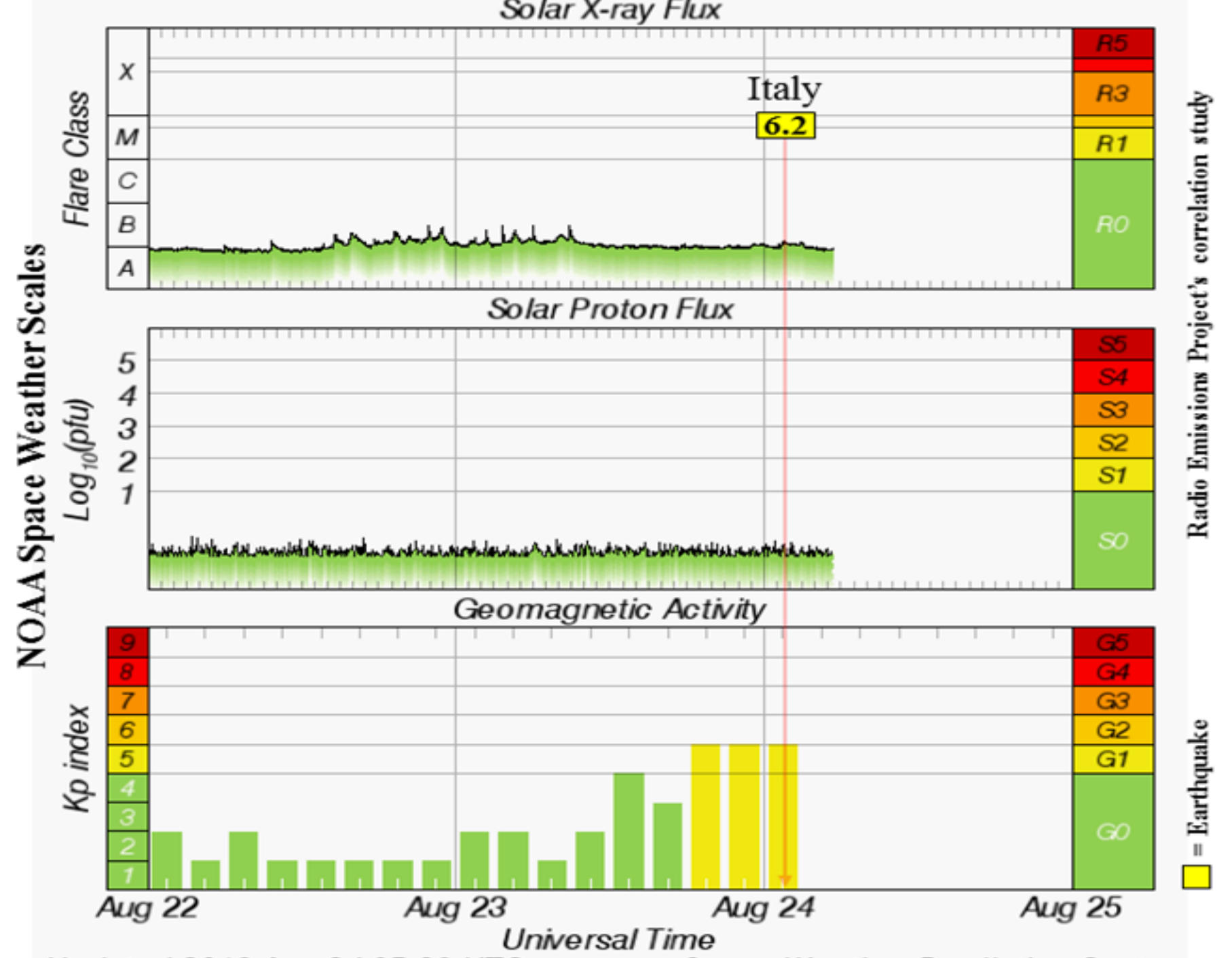

\section{Updated 2016 Aug 24 05:30 UTC}

Space Weather Prediction Center

Fig-8. NOAA Space Weather Scales. The picture shows the data relative to the three scales used by the NOAA (National Oceanic and Atmospheric Administration) to compute the intensity and type of solar and geomagnetic event to which humanity is exposed. If you observe the scale associated to Eart's geomagnetic activity is possible to understand that the Italian M6.2 earthquake occurred on August 24,2016 was preceded by a G1 geomagnetic storm started later than 18:00 UTC on August 23, 2016 that preceded the strong Italian earthquake about 7 hours and 36 minutes. Credits: Space Weather Prediction Center (SWPC).

Source: http://www.ltpaobserverproject.com/natural-hazard-monitor.html

\section{Interplanetary Magnetic Field (I.M.F.) Variation}

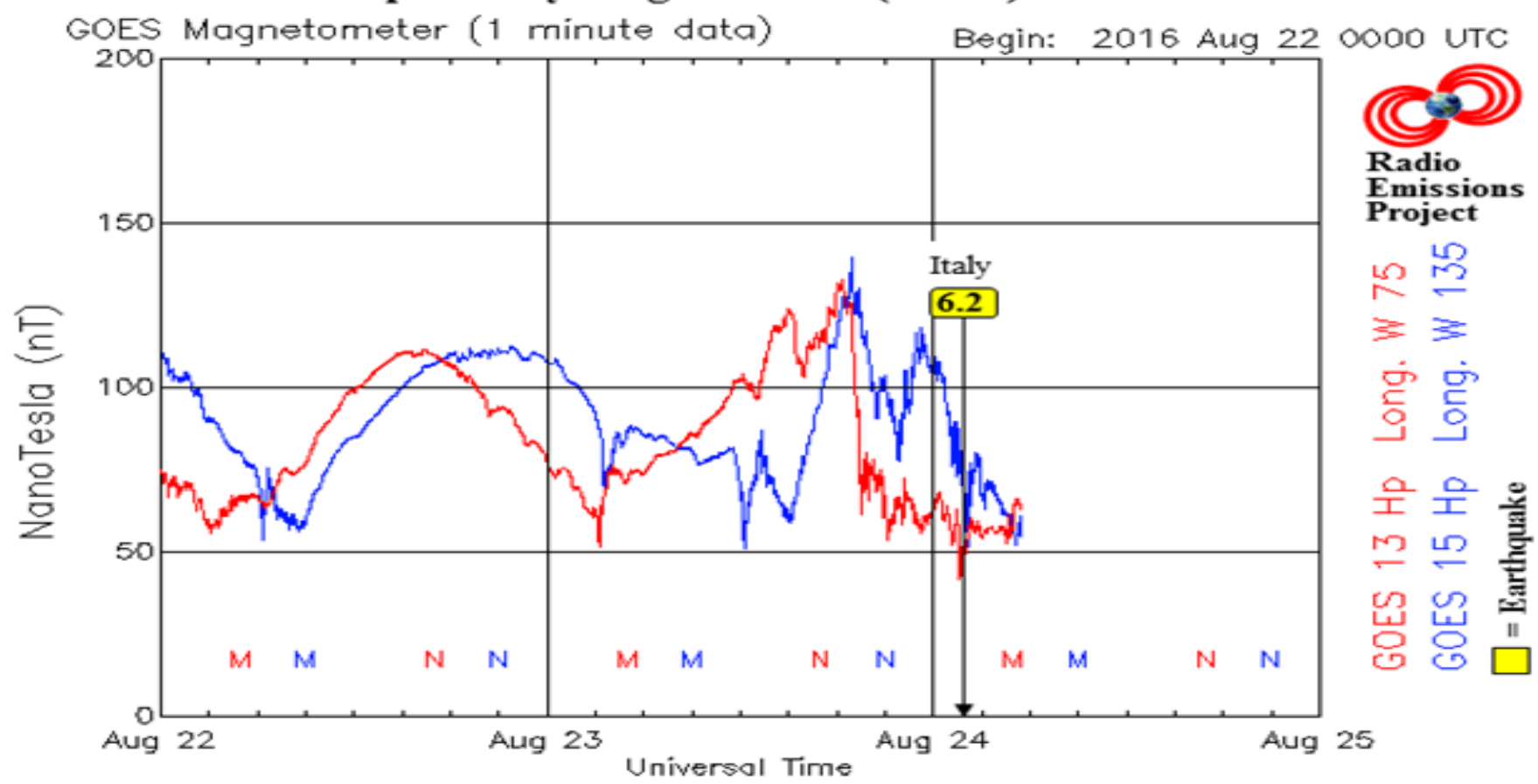

Updated 2016 Aug 24 05:30:02 UTC

NOAA/SWPC Boulder, CO USA

Fig-9. Interplanetary Magnetic Field (IMF) variation correlated to Italian M6.2 earthquake. The picture shows the magnetogram on the interplanetary magnetic field (IMF) that was recorded by the GOES-13 and GOES-15 satellites between 22 and 24 August 2016 . The black vertical arrow represents the temporal markers of the Italian earthquake M6.2 recorded on August 24, 2016 at 01:36 UTC. The graph shows a disturbance in the interplanetary magnetic field that preceded the Italian earthquake of about 20 hours.

Source: http://www.ltpaobserverproject.com/natural-hazard-monitor.html 


\section{Satellite Environment (3 Day)}
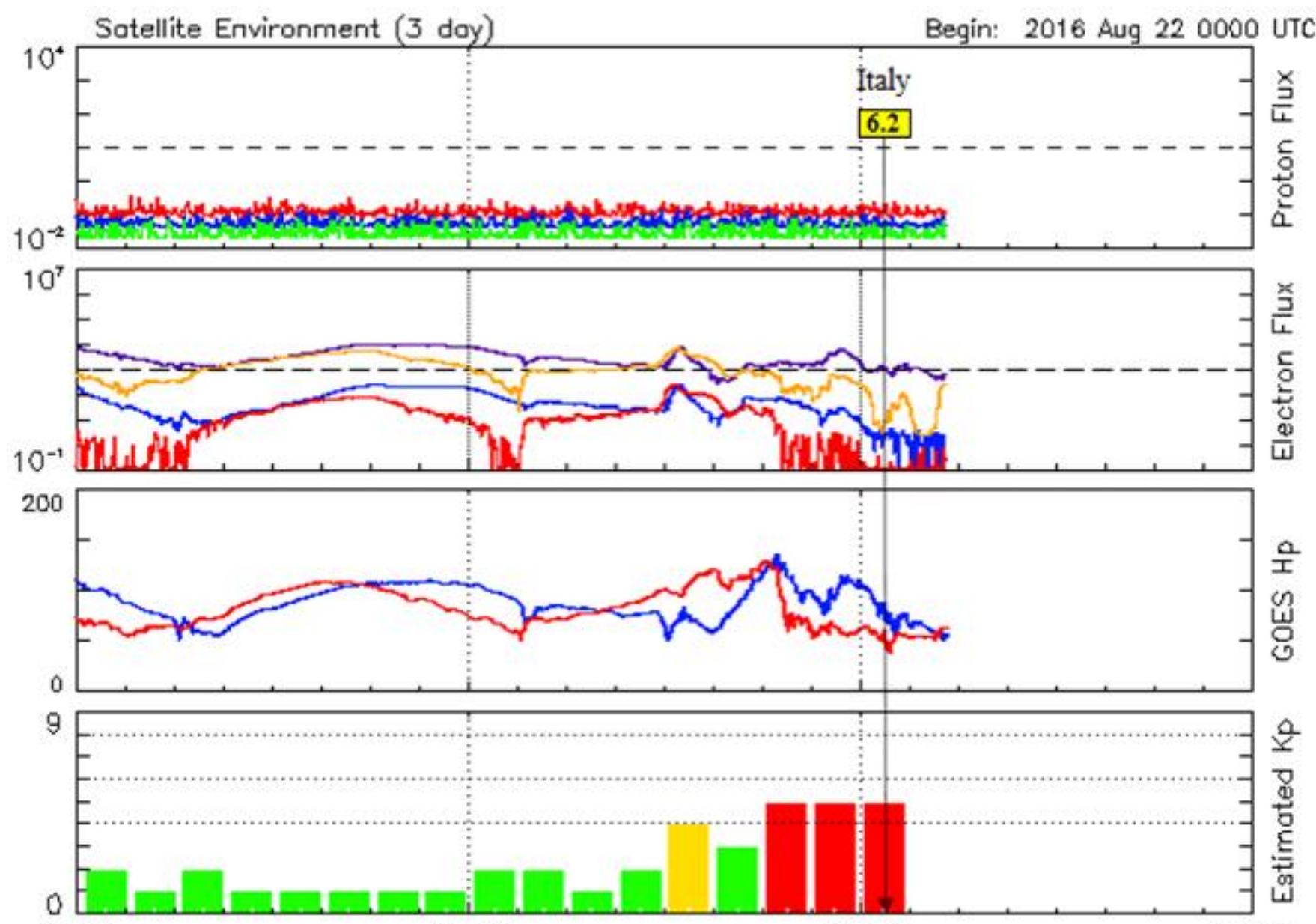

Aug 22

Aug 23

Aug 24

Updated 2016 Aug 24 05:26:05 UTC

\section{Universal Time}

\section{= Earthquake}

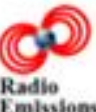

Aug 25

NOAA/SWPC Boulder, CO USA

Fig-10. Satellite environment. The image shows the graphs relating to the variation of the interplanetary magnetic field (IMF), to the variation of the solar wind ion density registered through GOES-13 and GOES-15 satellites and the Kp-Index. The long black vertical arrow represents the temporal markers of Italian M6.2 earthquake recorded on August 24, 2016 at 01:36 UTC.

Source: $\underline{\text { http://www.ltpaobserverproject.com/natural-hazard-monitor.html }}$

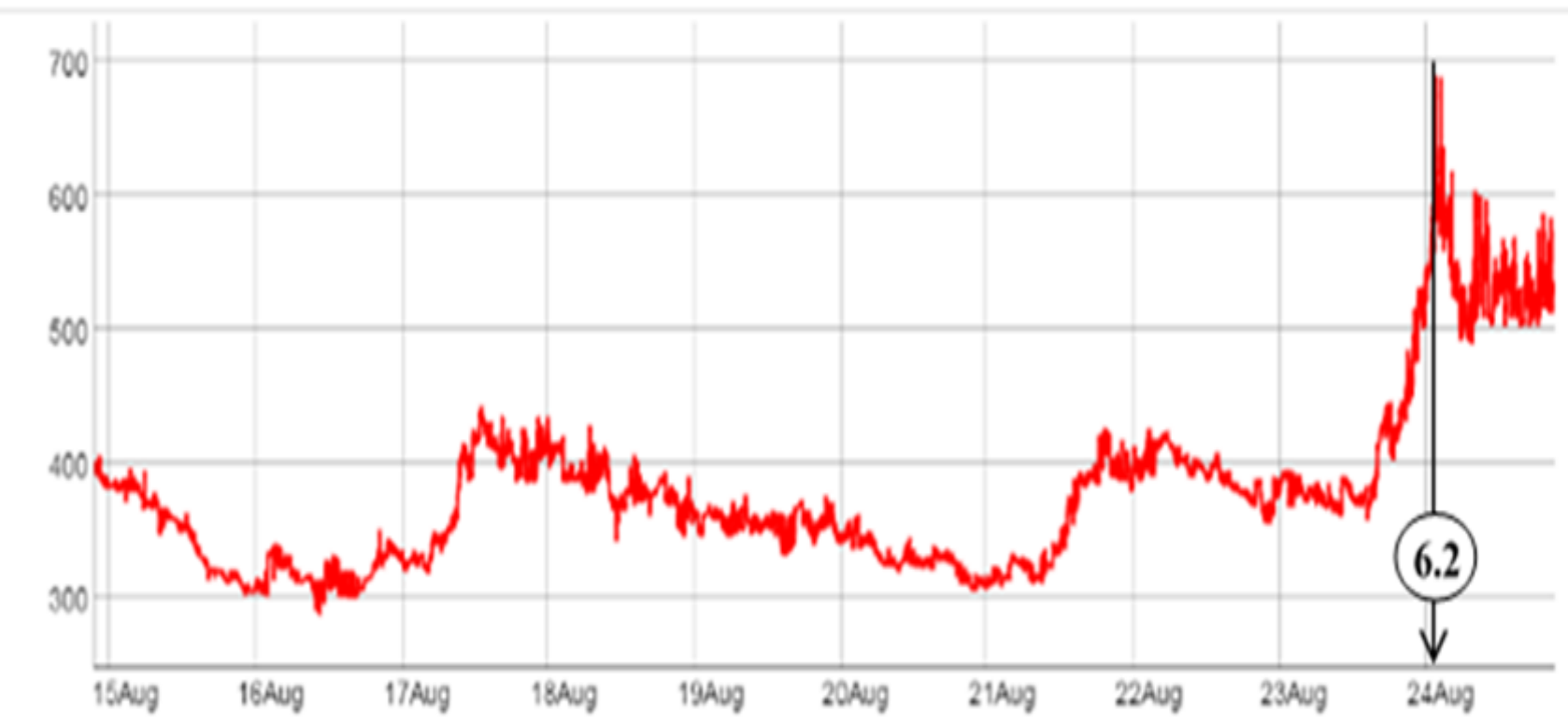

Fig-11. Solar Wind Velocity. The picture shows the graph of the solar wind speed recorded between 15 and 24 August 2016 near Earth. The vertical black arrow represents the temporal markers of Italian M6.2 earthquake recorded on August 24, 2016 at 01:36 UTC. Credits: iNtegrated Space Weather Analysis System (iSWA) Timeline Interactive.

Source: http://iswa.ccmc.gsfc.nasa.gov/IswaSystemWebApp/ 


\section{Emispheric Power in Gigawatt}

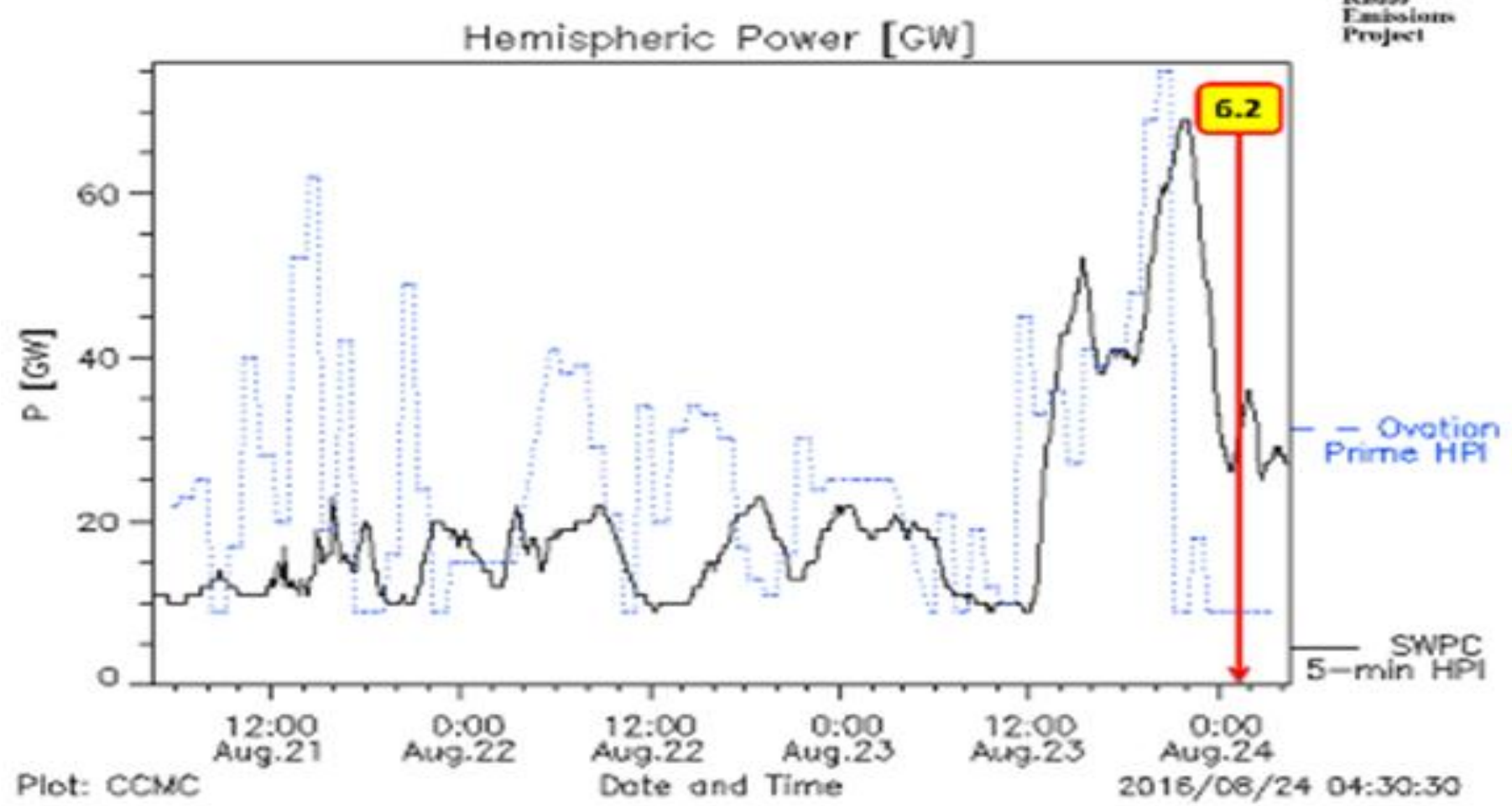

Dote and Time

$2016 / 08 / 2404: 30: 30$

Fig-12. Hemispheric Power in Gigawatt. The picture shows the graph of electromagnetic power emitted by terrestrial hemispheres registered (between 21 and 24 August 2016) through the Polar-orbiting Operational Environmental Satellites (POES), placed in a polar orbit at about 520 miles of altitude. The vertical red arrow represents the temporal markers of Italian M6.2 earthquake recorded on August 24, 2016 at 01:36 UTC. Credits: iNtegrated Space Weather Analysis System (iSWA).

Source: http://iswa.ccmc.gsfc.nasa.gov/IswaSystemWebApp/

\section{Earth's Geomagnetic Field Variation}

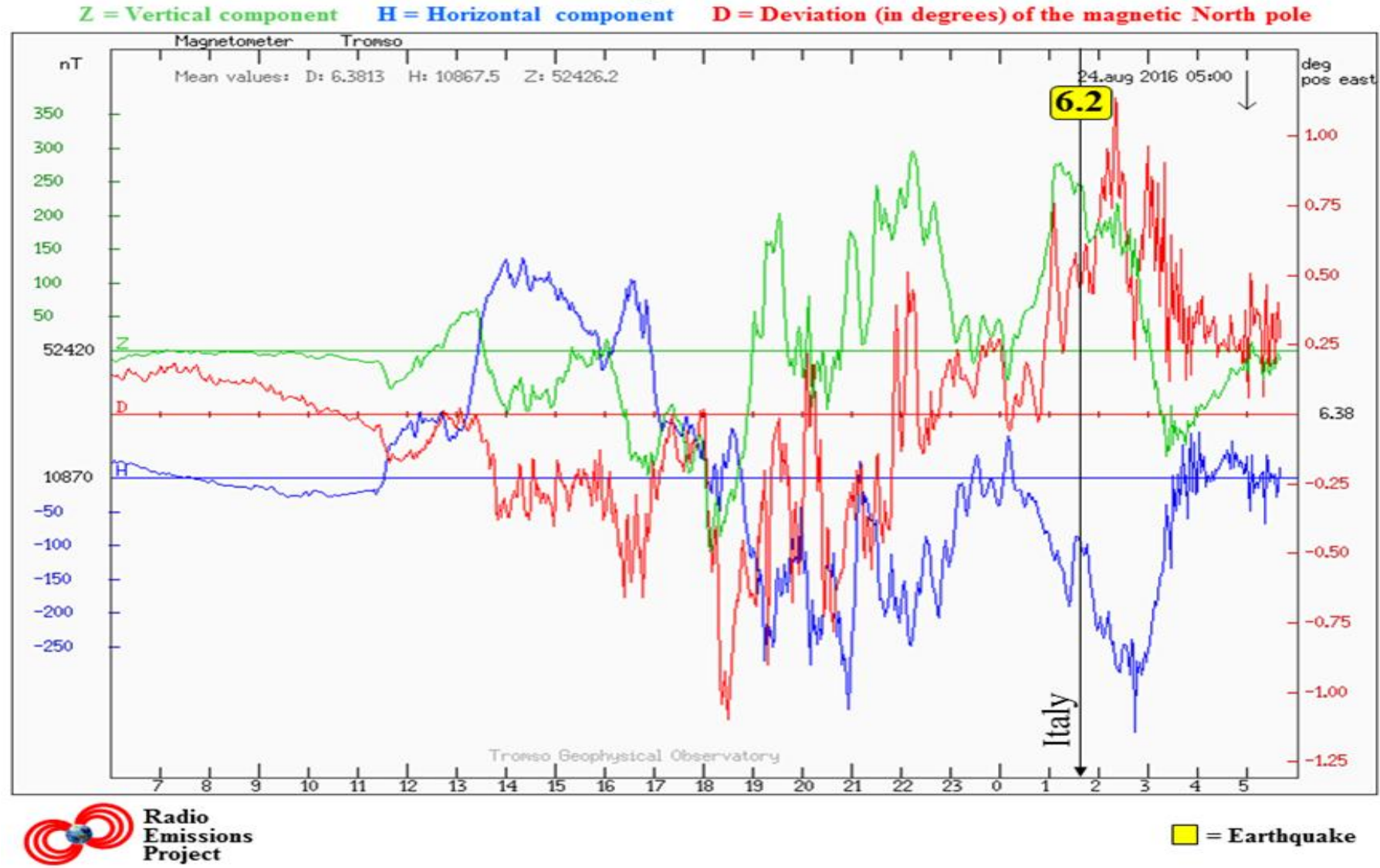

Fig-13. Earth's geomagnetic field variation recorded by Tromso Geomagnetic Observatory. Magnetogram containing the variation of the Earth's geomagnetic field, relative to Z (green line), H (blue line) and D (red line) component, registered by the Troms $\varnothing$ Geomagnetic Observatory (TGO), Norway, between 23 and 24 August 2016. The Z component is a vertical component, assumed positive when it's directed towards the inside of the Earth. The $\mathrm{H}$ component is the horizontal component, namely the component aligned in the direction of the magnetic North. The $\mathrm{D}$ component is magnetic declination angle between the direction of $\mathrm{H}$ and the geographic meridian passing through the point in question (Troms $\varnothing$ Geomagnetic Observatory), taken as positive when $\mathrm{H}$ is directed to the East of the geographic Nord. The vertical black lines represent the temporal markers of M6.2 earthquakes occurred in Italy on August 24, 2016; while the numbers represent the magnitude (Mw) of earthquakes.

Source: http://www.ltpaobserverproject.com/natural-hazard-monitor.html 


\section{Earth's Geomagnetic Field Variation}

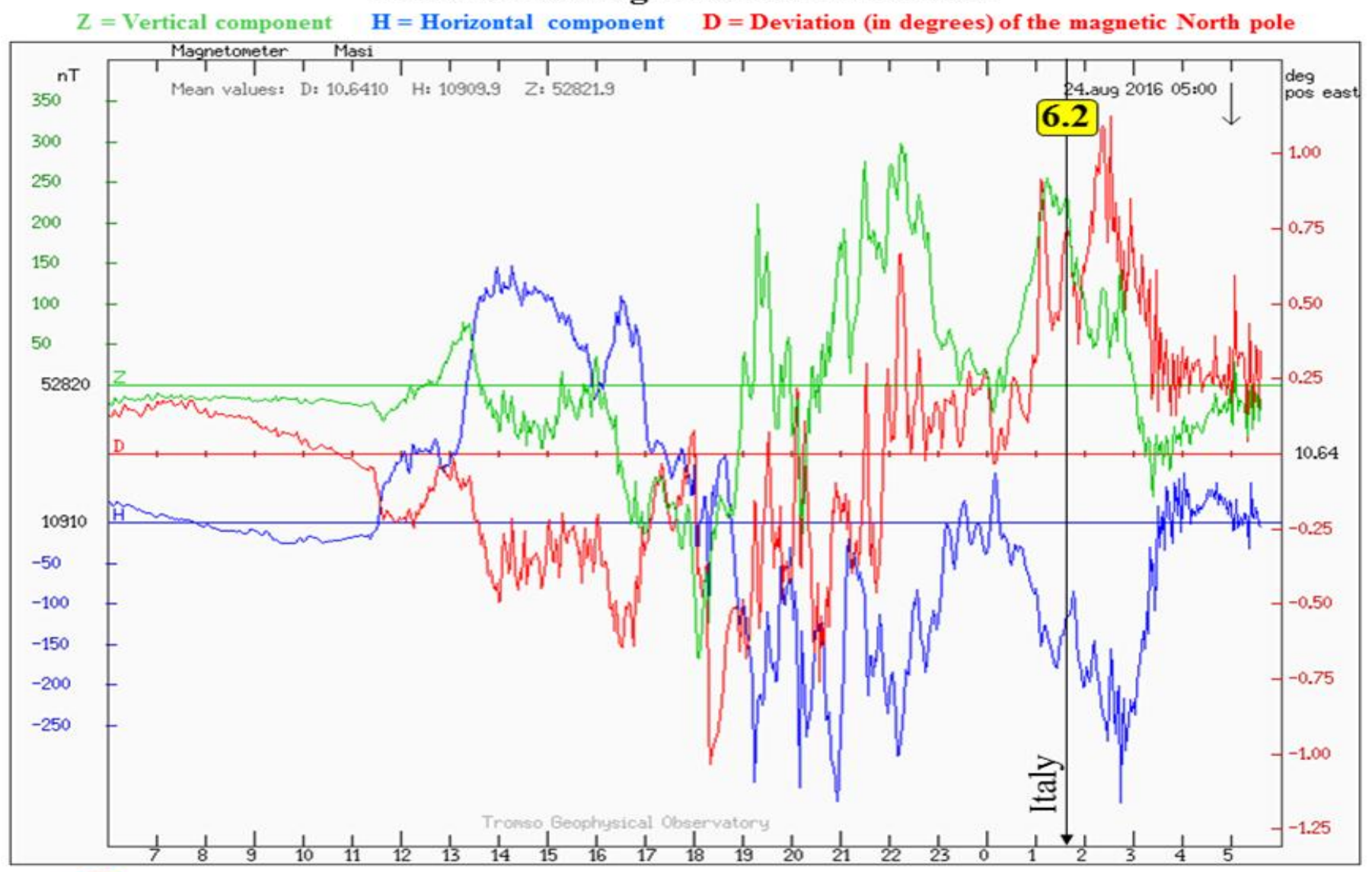

\section{(C) Radio}

Fig-14. Earth's geomagnetic field variation recorded by Masi Geomagnetic Observatory. Magnetogram containing the variation of the Earth's geomagnetic field, relative to Z (green line), $\mathrm{H}$ (blue line) and D (red line) component, registered by the Masi Geomagnetic Observatory (MAS), Norway, between 23 and 24 August 2016. The Z component is a vertical component, assumed positive when it's directed towards the inside of the Earth. The H component is the horizontal component, namely the component aligned in the direction of the magnetic North. The $\mathrm{D}$ component is magnetic declination angle between the direction of $\mathrm{H}$ and the geographic meridian passing through the point in question (Masi Geomagnetic Observatory), taken as positive when $\mathrm{H}$ is directed to the East of the geographic Nord. The vertical black lines represent the temporal markers of M6.2 earthquakes occurred in Italy on August 24, 2016; while the numbers represent the magnitude (Mw) of earthquakes.

Source: http://www.ltpaobserverproject.com/natural-hazard-monitor.html

\section{Radio Emissions Project's VLF Monitor}

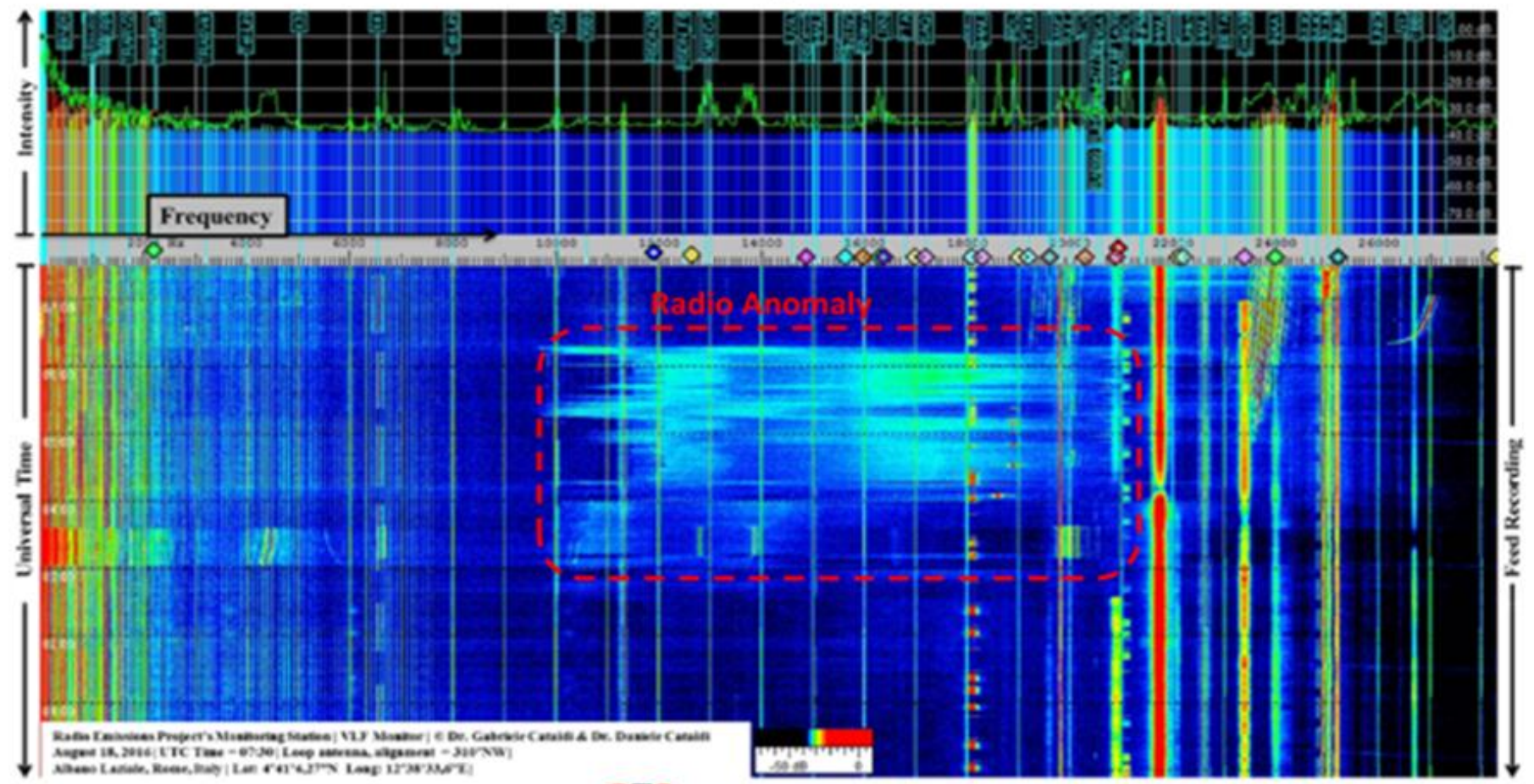

Natural and anthropic radio emissions monitoring.

Albano Laxiale, Rome, Italy.

Fig-15. VLF Monitor: The picture shows the dynamic spectrogram of the Earth's electromagnetic field recorded on August 18, 2016 between 00:00 and 07:30 UTC from the electromagnetic environment monitoring station of Radio Emissions Project, located at Albano Laziale (RM), Italy. At the center of the spectrogram, inside the red dotted line, is present the radio anomaly that has been recorded precede the M6.2 Italian earthquake occurred on August 24, 2016 at 01:36 UTC. The emission appeared at 02:47 UTC and disappeared at 06:21 UTC. The labels at the top of the spectrogram (in light blue) indicate known radio stations, prevalently of anthropic type. On the $\mathrm{Y}$ axis of the spectrogram indicates the UTC time of the registration; this proceeds from top to bottom at 1 horizontal line to minutes. On the X axis is instead reported the emission frequency of the radio signals (the frequency increases going to the right): these are represented in different colors according to their intensity.

Source: http://www.ltpaobserverproject.com/natural-hazard-monitor.html 


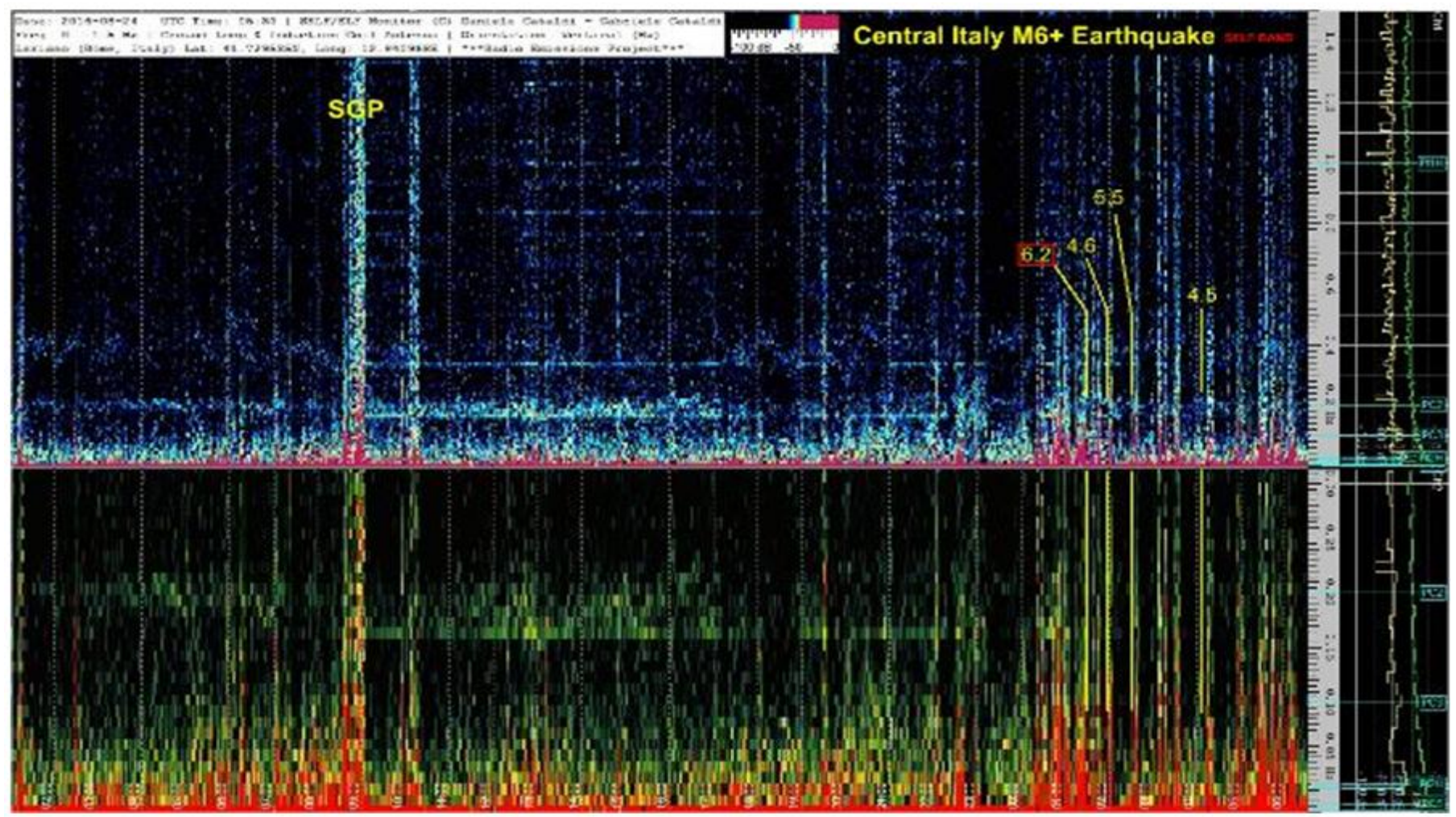

Fig-16. SELF-ELF Monitor. The image represents the dynamic spectrogram of the Earth's electromagnetic field registered between August 23 2016 at 02:00 UTC and August 24, 2016 at 06:30 UTC by environmental electromagnetic monitoring station of the Radio Emissions Project, located in Lariano (RM), Italy, which monitors the SELF band and ELF band with a resolution of 10,1 $\mathrm{mHz}$. The upper portion of the spectrogram is centered on the SELF band between 0 and $1,5 \mathrm{~Hz}$, while the lower portion is centered in the SELF band between 0 and SELF $0,31 \mathrm{~Hz}$. The spectrogram is acquired through a radio receiver prototype developed by Dr. Gabriele Cataldi designed to work efficiently between the band SELF $(0<\mathrm{f}<3 \mathrm{~Hz})$ and the ELF band $(3-30 \mathrm{~Hz})$. The used antenna is a coil antenna aligned vertically. The word "SGP" (Seismic Geomagnetic Precursor) is an acronym coined by the authors that identifies the radio emission of electromagnetic nature that are observed to precede large earthquakes. On the X axis of the spectrogram indicates the UTC time of the registration; this proceeds from right to left at 1 vertical line every 1,5 minutes. On the $\mathrm{Y}$ axis is instead reported the emission frequency of the radio signals (the frequency increases going in the top): these are represented in different colors according to their intensity.

Source: http://www.ltpaobserverproject.com/natural-hazard-monitor.html

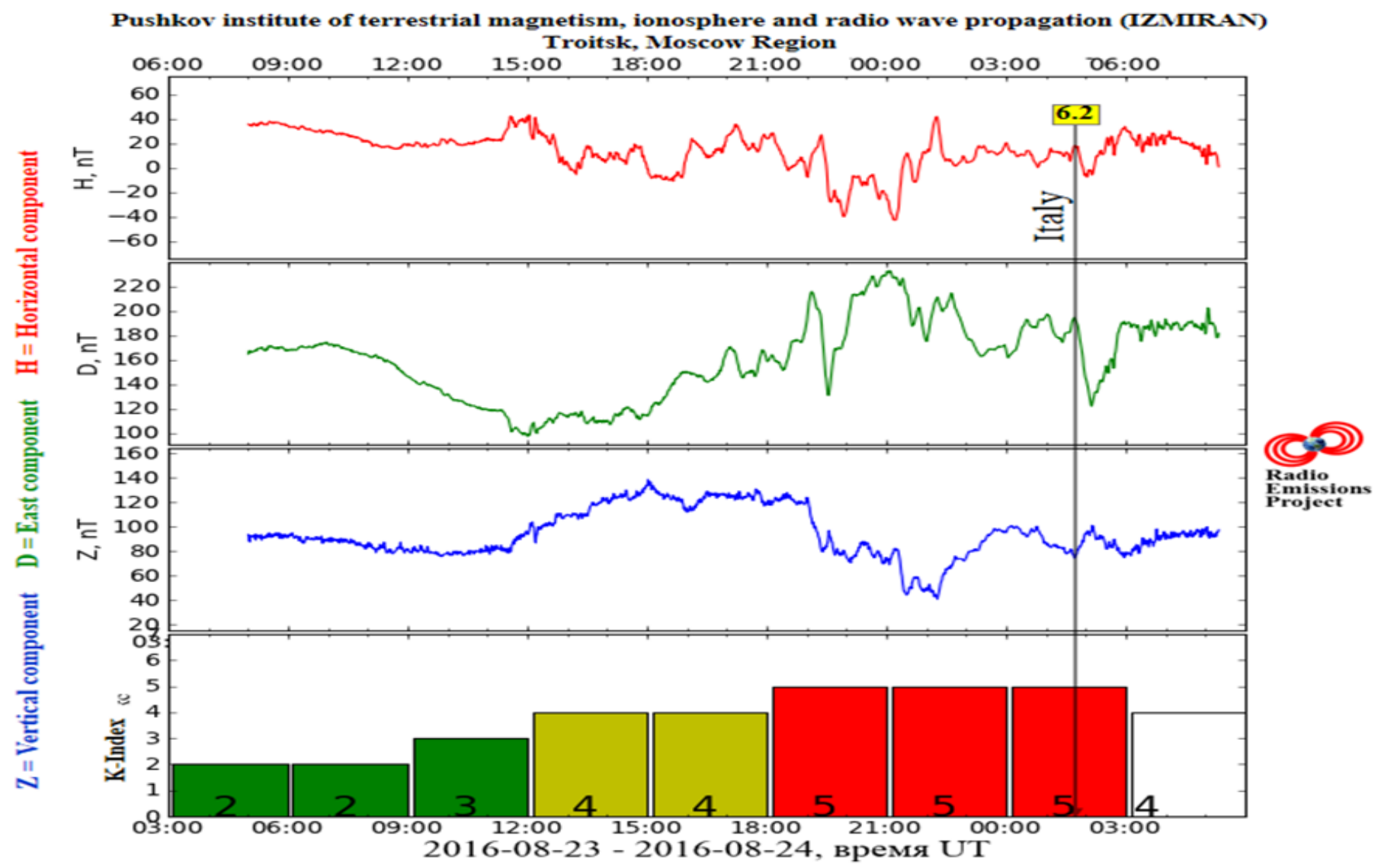

Universal Time

$\square=$ Earthquake

Fig-17. IZMIRAN Geomagnetic Observatory. The picture shows the variation of Earth's geomagnetic field (in natoTesla, nT) measured on the vertical axis $(\mathrm{Z})$, on the horizontal axis in the direction of the magnetic North pole $(\mathrm{H})$ and on the horizontal axis in the East direction (D) recorded between 03:00 UTC on August 23, 2016 and 03:45 UTC on August 24, 2016 by the Pushkov Institute of Terrestrial Magnetism, Ionosphere and Radio Wave Propagation (IZMIRAN), located at coordinates 54.3004N, 20.1208E. On the bottom image is instead present the K-Index, calculated by the observatory. The black vertical line represents the temporal markers of the Italian M6.2 earthquake recorded on August 24, 2016. It is clear that the Italian M6.2 earthquake was preceded by an increase of the K-Index, ie by an increase of the Earth's geomagnetic field that began on August 23, 2016 at 09:00 UTC.

Source: http://www.ltpaobserverproject.com/natural-hazard-monitor.html 


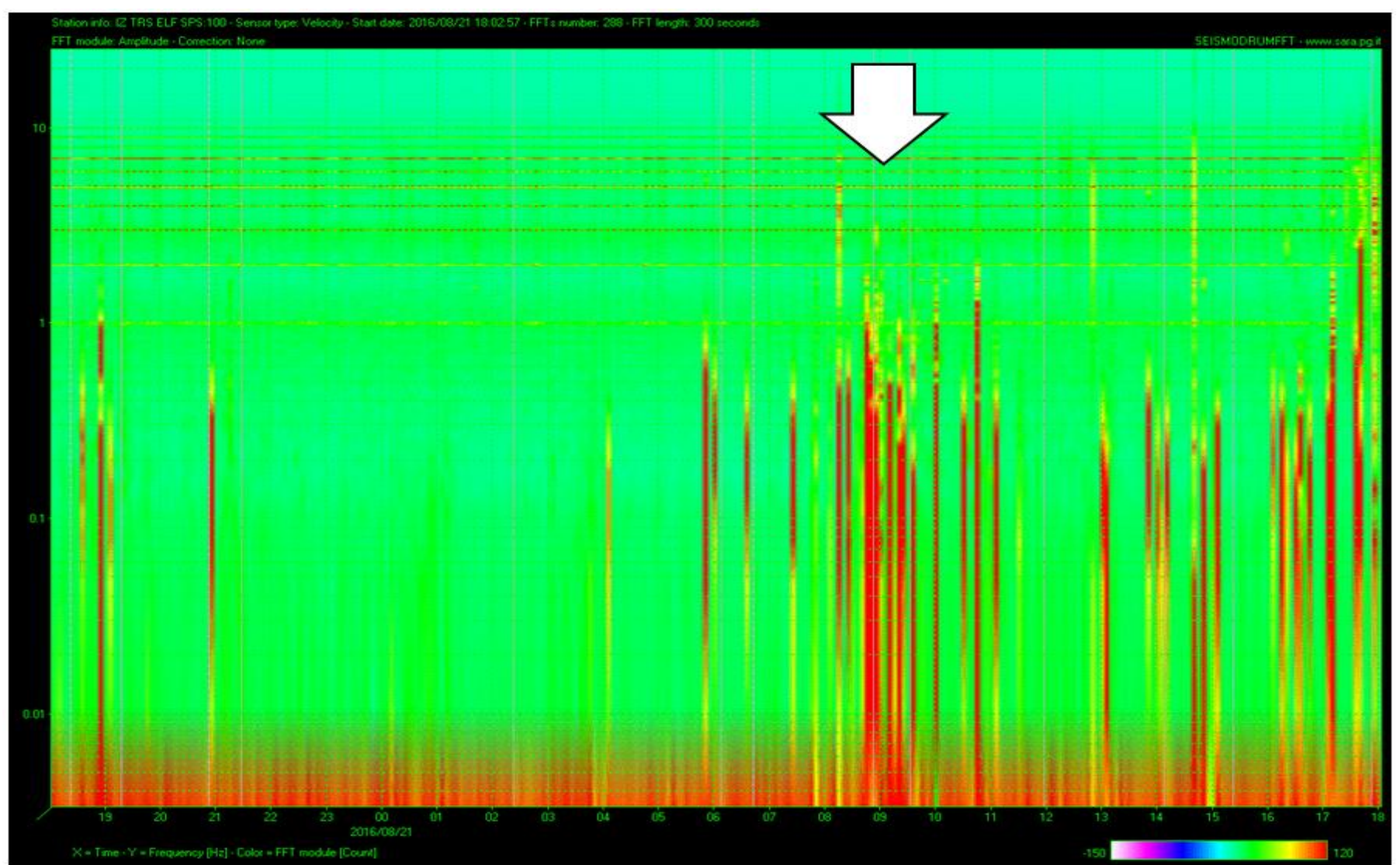

Fig-18. FESN's Geomagnetic Monitoring Station. The picture shows the dynamic spectrogram of the Earth's electromagnetic Field (SELFELF band) recorded between August 20, 2016 at 18:00 UTC and August 21, 2016 at 18:00 UTC by the environmental monitoring station of the electromagnetic Friuli Experimental Seismic Network (FESN), located in Trasaghis (UD), Italy. The large white arrow visible at the top indicates electromagnetic anomaly that has been captured by FESN station on August 21, 2016 between 08:40 UTC and 09:35 UTC. In addition, between 10:45 UTC until 18:00 UTC were recorded some radio impulsive emissions. After 18:00 UTC recording has stopped and no further registration details available. On the X axis of the spectrogram indicates the UTC time of the registration; this proceeds from right to left. On the $\mathrm{Y}$ axis is instead reported the emission frequency of the radio signals (the frequency increases going in the top): these are represented in different colors according to their intensity.

Source: http://www.fesn.org/

\section{References}

[1] J. Milne, "Earthquakes in connection with electric and magnetic phenomena," 1890.

[2] M. Parrot, "Statistical study of ELF/VLF emissions recorded by a low-altitude satellite during seismic events," Journal of Geophysical Research, vol. 99, pp. 23,339-23,347, 1994.

[3] C. J. Rodger, N. R. Thomson, and R. L. Dowden, "A search for ELF/VLF activity associated with earthquakes using ISIS satellite data," Journal of Geophysical Research, vol. 101, pp. 13,369 - 13,378, 1996.

[4] Y. Fujinawa, T. Matsumoto, H. Iitaka, and S. Takahashi, "Characteristics of the earthquake related ELF/VLF band electromagnetic field changes, American geophysical union," presented at the Fall Meeting 2001. AGU, San Franscisco, CA, pp. \#S42A-0616, 2001.

[5] A. Rozhnoi, M. Solovieva, and M. Hayakawa, "The observation of Doppler shifts of subionospheric LF signal in possible association with earthquakes," Journal of Geophysical Research: Space Physics, vol. 117, 2012.

[6] C. S. Mavrodiev, L. Pekevski, and T. Jimseladze, Geomagnetic-quake as imminent reliable earthquake's precursor: Starring point for future complex regional network, electromagnetic phenomena related to earthquakes and volcanoes, Editor: Birbal Singh. New Delhi: Publ., Narosa Pub. House, 2008.

[7] H. Pranab and I. Tamanna, "Proton density variation in ionosphere before strong earthquake using GOES-15 data," Computational Advancement in Communication Circuits and Systems of the Series Lecture Notes in Electrical Engineering, vol. 335 pp. 185-195, 2015 .

[8] Y. Kasahara, F. Muto, T. Horie, M. Yoshida, M. Hayakawa, K. Ohta, A. Rozhnoi, M. Solovieva, and O. A. Molchanov, "On the statistical correlation between the ionospheric perturbations as detected by subionospheric VLF/LF propagation anomalies and earthquakes," Hazards Earth Syst. Sci., vol. 8, pp. 653-656, 2008.

[9] V. Straser, C. Gabriele, and C. Daniele, "Earthquakes unrelated to natural geomagnetic activity: A North Korean case," 2013.

[10] V. Straser, "Can IMF and the electromagnetic coupling between the sun and the earth cause potentially destructive earthquakes?," ed. Society for Interdisciplinary Studies (SIS) New Concepts in Global Tectonics Newsletter, No. 65. Terenzo PR, Italy, 2012.

[11] V. Straser and G. Cataldi, Solar wind proton density increase and geomagnetic background anomalies before strong M6+ earthquakes. Moscow, Russia: Space Research Institute of Moscow, Russian Academy of Sciences, MSS-14. $2014,2014$.

[12] V. Straser and G. Cataldi, "Solar wind ionic variation associated with earthquakes greater than magnitude M6.0," New Concepts in Global Tectonics Journal, vol. 3, pp. 140-154, 2015.

[13] V. Straser, G. Cataldi, and D. Cataldi, "Radio-anomalies: Tool for earthquakes and tsunami forecasts," European Geosciences Union (EGU) General Assembly 2015, Natural Hazard Section (NH5.1), Sea \& Ocean Hazard - Tsunami, Geophysical Research Abstract, Vol. 17, Vienna, Austria. Harvard-Smithsonian Center for Astrophysics, High Energy Astrophysics Division, SAO/NASA Astrophysics Data System2015.

[14] V. Straser, "Radio anomalies and variations in the interplanetary magnetic field used as seismic precursor on a global scale," New Concepts in Global Tectonics Newsletter, no. 61, December, 2011. Terenzo PR, Italy, 2011.

[15] G. Cataldi, D. Cataldi, and V. Straser, Variations of terrestrial geomagnetic activity correlated to M6+ global seismic activity. EGU (European Geosciences Union) 2013, general assembly, geophysical research abstracts vol. 15. Vienna, Austria: HarvardSmithsonian Center for Astrophysics, High Energy Astrophysics Division, SAO/NASA Astrophysics Data System, 2013.

[16] G. Cataldi, D. Cataldi, and V. Straser, Earth's magnetic field anomalies that precede the M6+ global seismic activity. European geosciences union (EGU) general assembly 2014, geophysical research abstract, natural Hazard section (NH4.3), Electro-magnetic phenomena and connections with seismo-tectonic activity vol. 16. Vienna, Austria: Harvard-Smithsonian Center for Astrophysics, High Energy Astrophysics Division, SAO/NASA Astrophysics Data System, 2014.

[17] T. Rabeh, G. Cataldi, and V. Straser, Possibility of coupling the magnetosphere-ionosphere during the time of earthquakes. European geosciences union (EGU) general assembly 2014, geophysical research abstract. Natural Hazard Section (NH4.3), Electro-magnetic phenomena and connections with seismo-tectonic activity vol. 16. Vienna, Austria: Harvard-Smithsonian Center for Astrophysics, High Energy Astrophysics Division, SAO/NASA Astrophysics Data System, 2014. 
[18] F. T. Freund, T. Akihiro, and L. W. S. Bobby, "Cracking the code of pre-earthquake low frequency EM emissions," 2005.

[19] F. T. Freund, "Pre-earthquake signals: Part 1. Deviatoric stresses turn rocks into a source of electric currents," Natural Hazards and Earth System Science, vol. 7, pp. $535-541,2007$.

[20] F. T. Freund, "Charge generation and propagation in rocks," Journal of Geodynamics, vol. 33, pp. 545-572, 2002.

[21] F. T. Freund, "On the electrical conductivity structure of the stable continental crust," Journal of Geodynamics, vol. 35, pp. 353-388, 2003.

[22] T. Bleier, C. Dunson, C. Alvarez, F. Freund, and R. Dahlgren, "Correlation of pre-earthquake electromagnetic signals with laboratory and field rock experiments," Natural Hazard and Earth System Sciences, vol. 10, pp. 1965-1975, 2010.

[23] G. Martelli and P. N. Smith, "Light, radiofrequency emission and ionization effects associated with rock fracture," Geophysical Journal International, vol. 98, pp. 397-401, 1989.

[24] V. Hadjicontis, C. Mavromatou, and D. Ninos, "Stress induced polarization currents and electromagnetic emission from rocks and ionic crystals, accompanying their deformation," Natural Hazards and Earth System Sciences SRef-ID: 1684-9981/nhess/2004-4633, vol. 4, pp. 633-639, 2004.

[25] M. B. Gokhberg, V. A. Morgounov, and O. A. Pokhotelov, Earthquake prediction: Seismoelectromagnetic phenomena. ReadingPhiladelphia: Gordon and Breach Science Publishers, 1995.

[26] M. Hayakawa and Y. Fujinawa, Electromagnetic phenomena related to earthquake prediction. Tokyo: Terra Scientific Publ, 1994.

[27] R. Milan, S. Miland, M. Dragana, M. Saumitra, and B. Zeliko, "Astrophysical analysis of earthquake near Kraljevo (Serbia) on 3 November 2010," Journal of the Geographical Institute "Jovan Cvijić" SASA, vol. 61, pp. 1-15, 2011.

[28] K. Ohta, J. Izutsu, A. Schekotov, and M. Hayakawa, "The ULF/ELF electromagnetic radiation before the 11 March 2011 Japanese earthquake," Radio Science, vol. 48, pp. 589-596, 2013.

[29] E. M. Takla, K. Yumoto, J. Y. Liu, Y. Kakinami, T. Uozumi, S. Abe, and A. Ikeda, "Anomalous geomagnetic variations possibly linked with the Taiwan earthquake $(\mathrm{Mw}=6,4)$ on 19 December 2009," International Journal of Geophysics, vol. $2011,2011$.

[30] L. N. Makarova and A. V. Shirochkov, "On the connection between the earth's magnetosphere magnetopause position and the earthquakes occurrence," Abstracts of XXVI General Assembly LJRSI, Toronto, Canada, August 13-21, p. 755, 1999.

[31] G. Duma and Y. Ruzhin, "Diurnal changes of earthquake activity and geomagnetic Sq-variations," Natural Hazards and Earth System Science, vol. 3, pp. 171-177, 2003.

[32] N. Bijan, "Do solar activities cause local earthquakes? New Zealand," IJFPS, vol. 2, pp. 17-20, 2012.

[33] V. E. Khain and E. N. Khalilov, "About possible influence of solar activity upon seismic and volcanic activities: Long-term forecast," Science Without Borders. Transactions of the International Academy of Science H \&E, vol. 3, 2008.

[34] M. H. Jusoh and K. Yumoto, Abdul Hamid. N. S., H. Liu. Electromagnetic coupling on solar-terrestrial system: Possible effect on seismic activities. Nagoya, Japan: ISAP, 2012.

[35] M. Kovalyov and S. Kovalyov, "On the relationship between cosmic ray, solar activity and powerful earthquakes," Pshysics. Gen. Ph., 2015.

[36] Z. Gui-Qing, "Relationship between global seismicity and solar activities," Acta Seismologica Sinica, vol. 11, pp. $495-500,1998$.

[37] C. R. Dong and C. L. John, "New madrid seismic zone, central USA: The great 1811-12 earthquakes, their relationship to solar cycles, and tectonic settings," Global Climate Status Report (GCSR), Space and Science Research Corporation (SSRC), International Earthquake and Volcano Prediction Center2015.

[38] B. Davidson, K. U-Yen, and C. Holloman, "Relationship between M8+ earthquake occurrence and the solar polar magnetic fields." Retrieved from http://spaceweathernews.com/, 2015.

[39] B. Nikouravan, S. Pirasteh, and S. Mollaee, "The effect of solar cycle's activities on earthquake: A conceptual idea for forecasting," Disaster Advances, vol. 6, pp. 14-21, 2013.

[40] M. H. Jusoh and K. Yumoto, Possible correlation between solar activity and global seismicity. Lagos, Nigeria: Space Environment Research Center of Kyushu University, ISW/MAGDAS School, 2011.

[41] C. Fidani and R. Battiston, "Analysis of NOAA particle data and correlations to seismic activity," Natural Hazards and Earth System Science, vol. 8, pp. 1277-1291, 2008.

[42] N. J. Bijan, J. Rawal, S. Rahman, and N. Mahomud, "Probing relation between solar activities and seismicity," International Journal of the Physical Sciences, vol. 7, pp. 3082-3088, 2012.

[43] S. Odintsov, K. Boyarchuk, K. Georgieva, B. Kirov, and D. Atanasov, "Long-period trends in global seismic and geomagnetic activity and their relation to solar activity," Physics and Chemistry of the Earth, vol. 31, pp. 88-93, 2006.

[44] G. A. Sobolev, I. P. Shestopalov, and E. P. Kharin, "Geoeffective solar flares and seismic activity of the earth," Fiz. Zemli, vol. 7, pp. 85-90, 1998.

[45] G. A. Sobolev, N. A. Zakrzhevskaya, and E. P. Kharin, "On the relation between seismicity and magnetic storms," Phys. Solid Earth, Russian Acad. Sc., vol. 11, pp. 62-72, 2001

[46] A. I. Abdurakhmanov, L. P. Firstov, and V. A. Shirokov, "Possible connection of volcanic eruptions with 11 -year cyclicality of solar activity. In the book bulletin of volcanic stations," M., Science, vol. 52, pp. 3-10, 1976.

[47] S. V. Tzirel, About possible dependence of volcanic activity upon solar activity. In book Atlas of temporary variations of natural, anthropogenic and social processes vol. 3rd: M., Yanus-K, 2002.

[48] S. F. Mekhtiyev and E. N. Khalilov, "About possibility of detection of connection between volcanic eruptions and solar activity," Volcanology and Seismology, M, vol. 3, pp. 64-67, 1985. 